\title{
Customer System Efficiency Improvement Assessment: Supply Curves for Transmission and Distribution Conservation Options
}

November 1987

Prepared for the

Bonneville Power Administration under a Related Services Agreement with the U.S. Department of Energy Contract DE-AC06-76RLO 1830

Pacific Northwest Laboratory Operated for the U.S. Department of Energy by Battelle Memorial Institute 


\title{
DISCLAIMER
}

This report was prepared as an account of work sponsored by an agency of the United States Government. Neither the United States Government nor any agency thereof, nor Battelle Memorial Institute, nor any of their employees, makes any warranty, expressed or implied, or assumes any legal liability or responsibility for the accuracy, completeness, or usefulness of any information, apparatus, product, or process disclosed, or represents that its use would not infringe privately owned rights. Reference herein to any specific commercial product, process, or service by trade name, trademark, manufacturer, or otherwise, does not necessarily constitute or imply its endorsement, recommendation, or favoring by the United States Government of any agency thereof, or Battelle Memorial Institute. The views and opinions of authors expressed herein do not necessarly state or reflect those of the United States Government or any agency thereof, or Battelle Memorial Institute.

\author{
PACIFIC NORTHWEST LABORATORY \\ operated by \\ BATTELLE MEMORIAL INSTITUTE \\ for the \\ UNITED STATES DEPARTMENT OF ENERGY \\ under Contract DE-ACO6-76RLO 1830
}

\begin{tabular}{|c|c|}
\hline \multirow{2}{*}{\multicolumn{2}{|c|}{ Printed in the United States of America }} \\
\hline & \\
\hline \multicolumn{2}{|c|}{ Available from } \\
\hline \multicolumn{2}{|c|}{$\begin{array}{l}\text { United States Department of Commerce } \\
\text { Union Service }\end{array}$} \\
\hline $\mathbf{5 2 8 5}$ & ad \\
\hline Springf & 22161 \\
\hline \multirow{2}{*}{\multicolumn{2}{|c|}{$\begin{array}{l}\text { NTIS Price Codes } \\
\text { Microfiche A01 }\end{array}$}} \\
\hline & \\
\hline \multicolumn{2}{|c|}{ Printed Copy } \\
\hline & Price \\
\hline Pages & Codes \\
\hline 001-025 & $\mathrm{A} 02$ \\
\hline 026-050 & $\mathrm{A} 03$ \\
\hline 051-075 & A04 \\
\hline 076-100 & A05 \\
\hline $101-125$ & $\mathrm{~A} 06$ \\
\hline $126-150$ & A07 \\
\hline $151-175$ & $\mathrm{~A} 0 \mathrm{~B}$ \\
\hline $176-200$ & $\mathrm{~A} 09$ \\
\hline 201-225 & A010 \\
\hline $226-250$ & A011 \\
\hline 251-275 & A012 \\
\hline $276-300$ & A013 \\
\hline
\end{tabular}




\section{CUSTOMER SYSTEM EFFICIENCY IMPROVEMENT ASSESSMENT: SUPPLY CURVES FOR \\ TRANSMISSION AND DISTRIBUTION CONSERVATION OPTIJNS}

Authors:

R. C. Tepe? (a)

J. W. Callaway

J. G. De Steese

Technical

Contributors:

W. H. Doggett

M. J. King (b)

A. D. Lee

Z. T. Taylor

November 1987

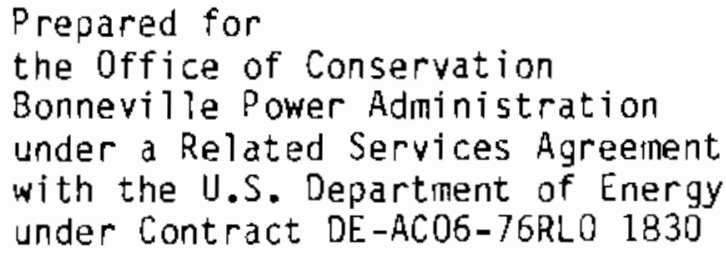

Pacific Northwest Laboratory

Richland, Washington 99352

(a) Now affiliated with Center for Naval Analyses, Alexandria, Virginia.

(b) Now affiliated with SYNERGIC Resources Corporation, Seattle, Washington. 
SUMMARY

This report documents the results of Task 6 in the Customer System Efficiency Improvement (CSEI) Assessment Project. A principal objective of this project, which is being conducted by the Pacific Northwest Laboratory (PNL) for the Office of Conservation, Bonneville Power Administration (BPA), is to assess the potential for energy conservation in the transmission and distribution (T\&D) systems of electric utilities in the BPA service area. The scope of this assessment covers BPA customers in the Pacific Northwest region and all nonfederaT TSD systems, including those that currently place no load on the BPA system.

Supply curves were developed to describe the conservation resource potentially available from T\&D-system efficiency improvements. These supply curves relate the levelized cost of upgrading existing equipment to the estimated amount of energy saved. Stated in this form, the resource represented by $T \& 0$ loss reductions can be compared with other conservation options and regional electrical generation resources to determine the most cost-effective inethod of supplying power to the Pacific Northwest. The development of the supply curves required data acquisition and methodology development that are also described in this report.

Four components, whose individual losses constitute the majority of total T\&D losses, were analyzed:

1. distribution transformers

2. substation transformers

3. primary feeders

4. transmission facilities (customer-owned).

Increasing the voltage of primary feeders that nominally operate at $12.5 \mathrm{kV}$ was evaluated as an alternative loss-reduction measure primarily to provide a benchinark for comparison with the costs and savings achievable from outright component replacement. Secondary feeders also can contribute a substantial amount to total losses, but because adequate information was not readily avai1able, andysis of conservation options for this system component was not undertaken. 
The conservation resources provided by the options considered were cotalad at two levels of cost: 2.0 and 5.5 cents/kwh in 1980 dollars. These costs correspond, in general, to the resource saturation points shown by the supply curves for the voltage upgrade and equipment replacement options, respectively.

A strict replacement program of distribution transformers, transmission lines, distribution feeders, and substation transformers with more efficient equipment yields a total recoverable resource of 233 average megawatts (AMW) at a cost of 5.5 cents/kWh. These savings are distributed as follows: distribution transformers can recover approximately 78 AMW; transmission lines, 48 ANW; distribution feeders, 99 AMW; and substation transformer, 8 AMli.

If operation of the $12.5 \mathrm{kV}$ portion ( $75 \%$ of the circuit niles) of the Pacific Northwest T\&D system were to be increased to $34.5 \mathrm{kV}$, the recoverable resource is considerably higher at 276 AMW. This loss-recovery option could be implemented at a cost of 2 cents/kWh. The cost estimate for this resource considered replacenent of transformers and insulators but was based on the use of existing poles and structures in the distribution system.

Because the postulated voltage upgrade affects only about $75 \%$ of customer utilities' circuit miles, additional conservation could be achieved by applying equipment replacement measures to the balance of the system. The combination of 1) upgrading the voltage of the current $12.5 \mathrm{kV}$ system, 2) replacing the renaining $25 \%$ of the region's distribution transformers, 3) reconductoring $25 \%$ of the primary feeders, 4) replacing substation transformers, and 5) reconductoring customer-owned transmission lines results in an estimated total conservation resource of $380 \mathrm{AMW}$ at 5.5 cents $/ \mathrm{kWh}$. Due to the dominance of the lower cost of the voltage upgrade, over $77 \%$ of this resource (293 AMW) is potentially available at a cost of 2 cents/kWh.

The loss-reduction potential of conservation measures can be considered to be equivalent to introducing new generating capacity. The Northwest Power Planning Council (NWPPC) has estabijished that T\&D system conservation may be a cost-effective alternative to capacity addition up to a cost of 5 cents/kin in 1985 dollars (NWPPC 1986). Allowing for $22 \%$ inflation in T\&D system costs 
between 1980 and 1985 ( 4 cents/kwh in $1980 \sim 5$ cents/kinh in 1985), :he T\&D system conservation potential in the Pacific Northwest, as estimated in this analysis, is 335 AMW at 5 cents/kWh in 1985 dollars.

The above analysis was extended to consider the T\&D conservation potential of publicly-owned utilities (POUs) separately. These are principally the public utility districts, rural electric cooperatives and municipally-owned systems known as "preference customers" that have the legal right of priority access to federally-generated power in the Pacific Northwest. The conservation potential of these systems is of special interest to BPA. This analysis indicated that POU resources are approximateiy $40 \%$ of the corresponding regional resources. The largest conservation resource available on poU systems resulted, as in the regional case, from the combination of the voltage upgrade resource with loss recovery provided by the replacement of the transformers and lines not affected by this measure. This combination indicated potential loss recovery of 125 and $150 \mathrm{AMW}$ at 2 and 5.5 cents/kWh, respectively, in 1980 dollars. At 5 cents/kWh in 1985 dotiars (the NWPPC cost-effectiveness criterion), the $T \& D$ conservation potential of POU systems was estimated to be approximately 140 AMw.

The supply function analysis performed in this study is dependent on the quality of the input data. The information used was collected by survey during Task 3 of the CSEI Project (Callaway and De Steese 1986). Biases present in this information could create biases in the supply curves. Overall, these biases and other assumptions in the analysis are considered to introduce a conservative tendency in the supply curves. The level of detail to which components were characterized and losses were estimated provides a more substantial basis than previously available, for assessing the conservation potential of customer T\&D systems in the BPA service area. 
- 


\section{ACKNOWLEDGMENTS}

The supply curve analysis reported in this document relied hedvily on the T\&D system characterization conducted in Task 3 of the CSEI Assessment Project. The authors acknowledge and appreciate the efforts of the many individuals in the Pacific Northwest utility industry who responded to the system characterization surveys and members of BPA's Area 0ffice staff, who facilitated these contacts. A number of PNL staff also contributed to this work, including Annet Dittmer, Elinor Edin, Audrey Lyke, Lisa Skumatz, and Jim Johnston. Cary Counts of PNL edited the manuscript.

Several nembers of BPA's headquarters staff, Camilla Downing and Barry Kennedy, in particular, assisted this research by providing helpful data and advice. The authors also thank the BPA Project Manager, Mike War'wick, for his continuing interest and encouragement during the course of the study. 



\section{OONTENTS}

SUMMARY $i \mathrm{i}$

ACKNOWLEDGMENTS $\ldots \ldots \ldots \ldots \ldots \ldots \ldots \ldots \ldots \ldots \ldots \ldots \ldots \ldots \ldots \ldots \ldots \ldots \ldots \ldots$

1.0 intRODUCTION $\ldots \ldots \ldots \ldots \ldots \ldots \ldots \ldots \ldots \ldots \ldots \ldots \ldots \ldots \ldots \ldots \ldots \ldots \ldots \ldots$

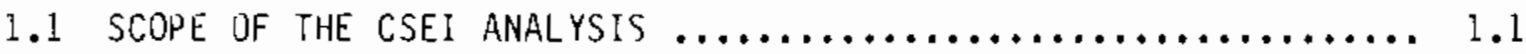

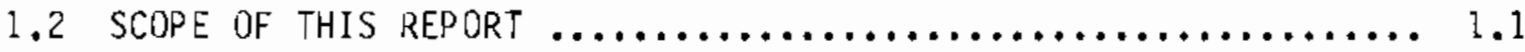

1.3 ORGANIZATION OF THIS REPORT $\ldots \ldots \ldots \ldots \ldots \ldots \ldots \ldots \ldots \ldots \ldots \ldots \ldots \ldots \ldots \ldots \ldots \ldots$

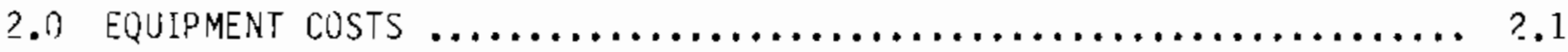

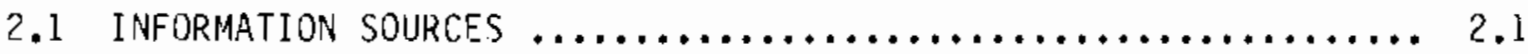

2.2 PROBLEMS ENCOUNTERED In ESTIMATING COSTS $\ldots \ldots \ldots \ldots \ldots \ldots \ldots \ldots .2$

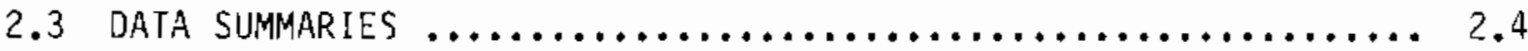

2.3 .1 Conductors $\ldots \ldots \ldots \ldots \ldots \ldots \ldots \ldots \ldots \ldots \ldots \ldots \ldots \ldots \ldots$

2.3 .2 Distribution Transformers $\ldots \ldots \ldots \ldots \ldots \ldots \ldots \ldots \ldots \ldots \ldots . \ldots \ldots$

2.3.3 Substation Transformers $\ldots \ldots \ldots \ldots \ldots \ldots \ldots \ldots \ldots \ldots . \ldots \ldots$

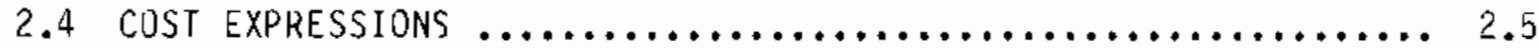

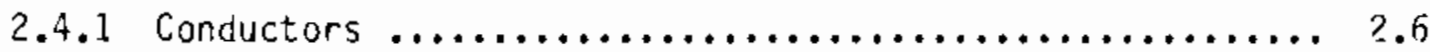

2.4.2 Distribution Transformers $\ldots \ldots \ldots \ldots \ldots \ldots \ldots \ldots \ldots \ldots . . . . . . \ldots$

2.4.3 Substation Transformers $\ldots \ldots \ldots \ldots \ldots \ldots \ldots \ldots \ldots \ldots \ldots \ldots$

3.0 NUMBERS AND TYPES OF EXISTING EQUIPMENT $\ldots \ldots \ldots \ldots \ldots \ldots \ldots \ldots \ldots \ldots . \ldots \ldots$

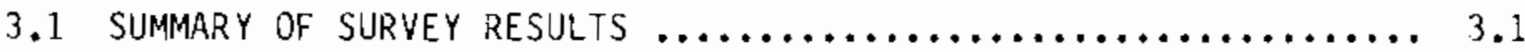

3.2 METHODOLOGY USED TO ESTIMATE NUMBERS AND TYPES
OF COMPONENTS $\ldots \ldots \ldots \ldots \ldots \ldots \ldots \ldots \ldots \ldots \ldots \ldots \ldots \ldots \ldots \ldots \ldots \ldots \ldots \ldots \ldots \ldots$

3.2.1 Identification of Component Categories $\ldots \ldots \ldots \ldots \ldots \ldots 3.3$

3.2 .2 Estination Procedures $\ldots \ldots \ldots \ldots \ldots \ldots \ldots \ldots \ldots \ldots \ldots \ldots . \ldots \ldots$

3.3 ESTIMATED NUMBER OF COMPONENTS BY SIZE $\ldots \ldots \ldots \ldots \ldots \ldots \ldots \ldots \ldots . .7$ 
7.0 DETERMINATIJN OF LOSSES AND DPERATING CHARACTEKISTICS $\ldots \ldots \ldots \ldots \ldots .1$

4.1 LOSS ESTIMATION METHOODLOGIES .................... 4.1

4.2 BACKGROUNO: T\&D SYSTEM LOSSES $\ldots \ldots \ldots \ldots \ldots \ldots \ldots \ldots \ldots \ldots \ldots \ldots . \ldots \ldots$

4.3 ASSUMPTIONS $\ldots \ldots \ldots \ldots \ldots \ldots \ldots \ldots \ldots \ldots \ldots \ldots \ldots \ldots \ldots \ldots \ldots \ldots$

4.3 .1 Distribution Transformers $\ldots \ldots \ldots \ldots \ldots \ldots \ldots \ldots \ldots . \ldots \ldots$

4.3 .2 Substation Transformers $\ldots \ldots \ldots \ldots \ldots \ldots \ldots \ldots \ldots \ldots . \ldots . . \ldots$

4.3 .3 Primary Feeders $\ldots \ldots \ldots \ldots \ldots \ldots \ldots \ldots \ldots \ldots \ldots \ldots \ldots \ldots . \ldots . \ldots \ldots$

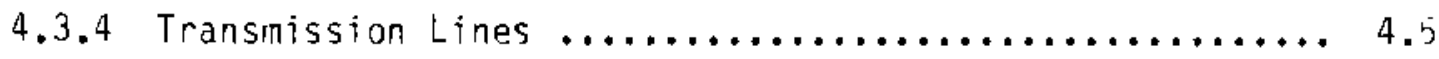

4.4 OPERATING CHARACTERISTICS OF EXISTING EqUIPMENT AND MORE
EFFICIENT EQUIPMENT $\ldots \ldots \ldots \ldots \ldots \ldots \ldots \ldots \ldots \ldots \ldots \ldots \ldots \ldots \ldots \ldots \ldots \ldots \ldots \ldots$

4.4.1 0istribution Transformer Characteristics .......... 4.5

4.4 .2 Substation Transformers $\ldots \ldots \ldots \ldots \ldots \ldots \ldots \ldots \ldots \ldots \ldots \ldots \ldots \ldots$

4.4.3 Primary Feeders and Transmission Lines ............ 4.12

4.5 ESTIMATED PER UNIT LOSSES FOR EXISTING AND REPLACEMENT
COMPONENTS $\ldots \ldots \ldots \ldots \ldots \ldots \ldots \ldots \ldots \ldots \ldots \ldots \ldots \ldots \ldots \ldots \ldots \ldots \ldots \ldots \ldots \ldots \ldots \ldots \ldots$

4.5 .1 Transformer Losses ........................ 4.13

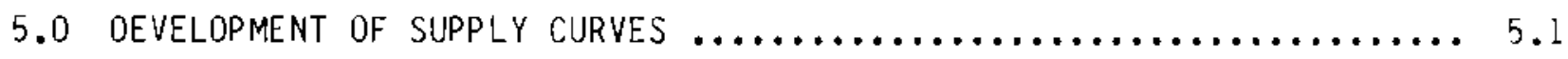

5.1 VINTAGES OF EXISTING EQUIPMENT $\ldots \ldots \ldots \ldots \ldots \ldots \ldots \ldots \ldots \ldots \ldots \ldots \ldots$

5.2 PAYMENT STREAM FOR REPLACING EQUIPMENT $\ldots \ldots \ldots \ldots \ldots \ldots \ldots \ldots . . . \ldots$

5.2.1 Standard-Efficiency Equipment Costs ............ 5.5

5.2 .2 High-Efficiency Equipment Costs .............. 5.5

5.3 AVERAGE POWER AND ENERGY SAVINGS $\ldots \ldots \ldots \ldots \ldots \ldots \ldots \ldots \ldots \ldots \ldots \ldots$

6.0 RESULTS OF SUPPLY CURVE ESTIMATION $\ldots \ldots \ldots \ldots \ldots \ldots \ldots \ldots \ldots \ldots \ldots \ldots \ldots \ldots$

6.1 DISTRIBUTION TRANSFORMER REPLACEMENT $\ldots \ldots \ldots \ldots \ldots \ldots \ldots \ldots \ldots$

6.2 TRANSMISSiON LINE REPLACEMENT $\ldots \ldots \ldots \ldots \ldots \ldots \ldots \ldots \ldots \ldots \ldots \ldots . \ldots$

6.3 DISTRIBUTION FEEDER REPLACEMENT $\ldots \ldots \ldots \ldots \ldots \ldots \ldots \ldots \ldots \ldots \ldots \ldots .4$ 
6.4 SUBSTATIUn tRANSFORMER REPLACEMENT $\ldots \ldots \ldots \ldots \ldots \ldots \ldots \ldots \ldots, 6.7$

6.5 COMBINED TRANSFORMER AND LINE REPLACEMENT $\ldots \ldots \ldots \ldots \ldots \ldots \ldots . .8$

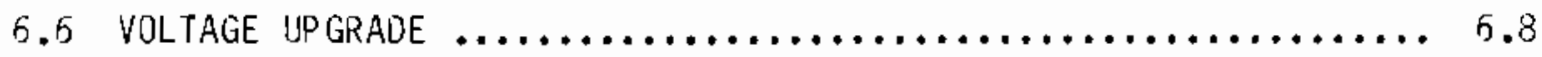

6.7 COMBINED VOLTAGE UPGRADE AND EQUIPMENT/LINE REPLACEMENT $\ldots \ldots .6 .10$

6.3 COST-EFFECTIVENESS OF CONSERVATION RESOURCES $\ldots \ldots \ldots \ldots \ldots \ldots .6 .12$

6.9 PUBLICLY-OWNED UTILITY T\&D SYSTEM EFFICIENCY IMPROVEMENTS $\ldots \ldots .6 .13$

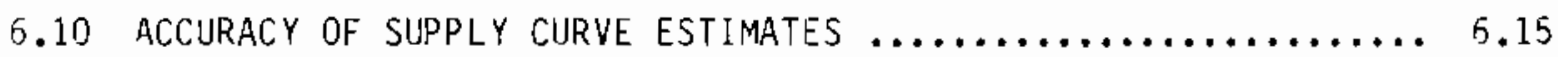

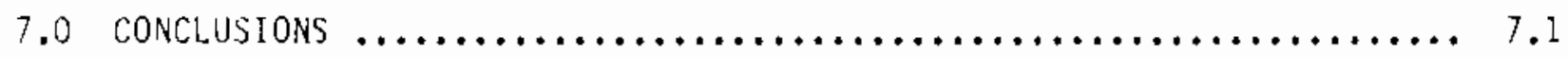

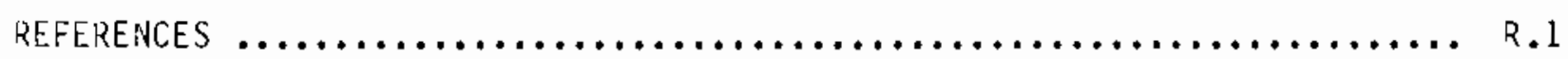

APPENDIX - LOSS REDUCTION METHOOOLOGY .......................... A.1 


\section{FIGURES}

1.1 Analytical Steps and Flow Chart for Supply Curve Estimation ....... 1.4

5.1 Input Steps for Development of the Supply Curves $\ldots \ldots \ldots \ldots \ldots \ldots . \ldots .2$

5.2 Age Distribution of Distribution Transformers .............. 5.4

6.1 Supply Curve for Replacernent of Standard-Efficiency Distribution Transformers with High-Efficiency Units .................... 5.3

6.2 Supply Curves for Replacement of Existing Transmission Lines with New Lines that Are 3,5, and 7 sizes Larger $\ldots \ldots \ldots \ldots \ldots \ldots \ldots .5$

6.3 Supply Curve for Replacement of Existing Feeder Line with New Lines that Are 3 Sizes Larger ........................ 6.6

6.4 Supply Curve for Replacement of Standard-Efficiency Substation Transformers with High-Efficiency Units .................. 6.7

6.5 Supply Curve for Combined Transformer and Line Replacement ....... 6.9

6.6 Supply Curve for Voltage Upgrade of the Existing $12.5 \mathrm{kV}$ System

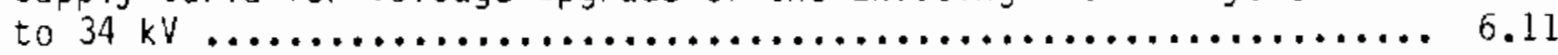

6.7 Supply Curve for Voltage Upgrade Combined with Replacement of the Balance of Transformers and Lines ......................... 6.12

6.8 Supply Curve for Voltage Upgrade Combined with Replacement of the

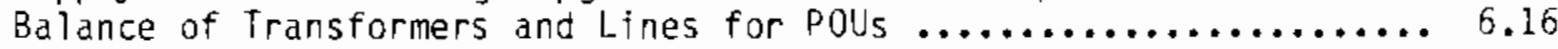


. 


\section{TABLES}

2.1 Functions for Determining Current-Carrying Capacity and

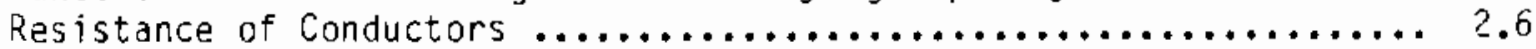

2.2 Manufacturer's Efficiency Factors Load Losses $\ldots \ldots \ldots \ldots \ldots \ldots \ldots . . . .2$

3.1 Number of Utilities and Percent of Estimated Total in Sample Data, by Component $\ldots \ldots \ldots \ldots \ldots \ldots \ldots \ldots \ldots \ldots \ldots \ldots \ldots \ldots \ldots \ldots \ldots \ldots . .3$

3.2 Size Categories of Distribution System Components $\ldots \ldots \ldots \ldots \ldots \ldots .4 .4$

3.3 Results of Regressions of Customers Against Quantity of

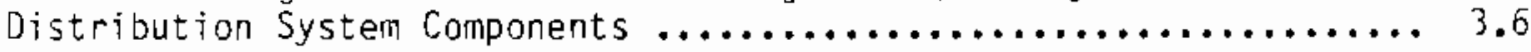

3.4 Estimated Number of Components in the BPA Region $\ldots \ldots \ldots \ldots \ldots \ldots . . .8$

4.1 Distribution Transformers: Categories and Estimated Operating Characteristics of Regional Stock $\ldots \ldots \ldots \ldots \ldots \ldots \ldots \ldots \ldots \ldots . \ldots . . .7$

4.2 Substation Transformers: Categories and Operating

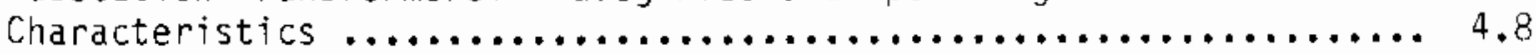

4.3a Primary Feeders: Operating Characteristics of Sample Data ........ 4.9

4.3b Primary Feeders: Categories and Estimated Operating

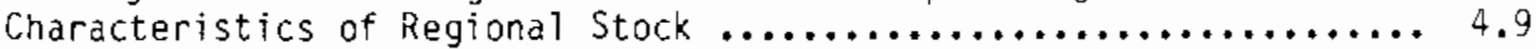

4.4a Transmission Lines: Operating Characteristics of Sample Data ..... 4.10

4.4b Transimission Lines: Categories and Estimated Operating

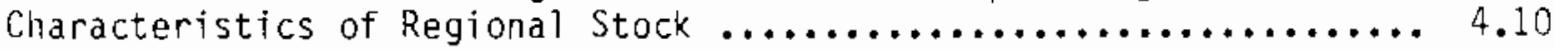

4.5 Estimated Annual Energy Losses and Loss Recovery ............... 4.13

6.1 Loss Recovery Potential and Cost of Pacific Northwest Regional T\&D System Efficiency Improvements $\ldots \ldots \ldots \ldots \ldots \ldots \ldots \ldots . \ldots .1$

6.2 Loss Recovery Potential and Cost of POU T\&D System Efficiency

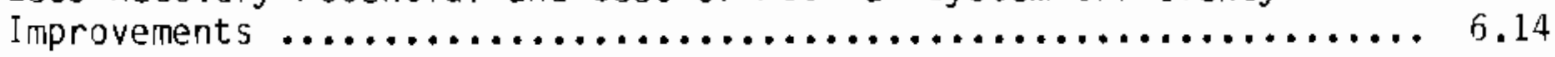

6.3 Percentage of Regional T\&D Conservation Resources Available on POU Systems in the BPA Service Area ....................... 6.15 


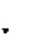




\subsection{INTRODUCTION}

This report documents the results of Task 6 of the CSEI Assassment Project, which is being conducted by PNL for the BPA Office of Conservation. A principal objective of the CSEI Assessment Project is to assess the potential for conservation in the T\&D systems of BPA's customers. The CSEI Project conplements BPA's ongoing assessment of the conservation potential in the residential, comercial, agricultural, and industrial sectors and in its own electric power transmission and generation systen. A second reason for the project was to respond to Action Item 11.2 in the 1983 Northwest Conservation and Electric Power plan issued by the NWPPC (1983). In Action Itam 11.2, the NWPPC requested that $B P A$ study potential improvements in the efficiency of electric power generation, transmission, and distribution. The CSEI Project focuses on all T\&D systems in the Pacific Northwest except systerns owned by the federal goverment.

\subsection{SCOPE OF THE CSEI ANALYSIS}

The goal of the CSEI Project is to assess and develop estimates of the magnitude, cost, and availability of the electric power conservation potential in customer T\&D systems. The assessment addresses improvements from several different perspectives, each of which will be evaluated in a separate report. In general, the study encompasses the following efforts: 1) a scoping assess-

ment of the general level of regional $T \& D$ losses and the resource that could be recovered by distribution transformer and feeder replacement, 2) a determination and evaluation of institutional factors that could constrain programmatic acquisition of the loss-reduction resource, 3) a survey to provide better estimates of the size and operating characteristics of the regional stock of T\&D components, and 4) the construction of supply curves defining the size and costs of the estimated recoverable resource.

\section{1.? SCOPE OF THIS REPORT}

This report describes the research efforts and the results of the supply curve analysis. In general terms, the purpose of a supply curve is to identify 
the relationship betiveen the availability of various iuantities of a jiven product and the costs required to acquire the product. In the context of Pacific Northwest regional power planning, conservation of electrical energy has been defined as a resource that is equivalent to thermal or hydropower generation and other sources of electricity. Like these other sources of electrical power, conservation resources may be acquired at various costs to the region by $B P A$, utility customers, and regional rate payers. Conservation through T\&D loss reduction can be obtained primarily through: 1) system management practices, 2) operationa! modifications, and 3) the replacement of existing equipment with components that are more efficient. The CSEI study described in this report addressed the latter two approaches.

Specifically, this report describes data development and the methodology chosen for determining the amount of lost energy resource available for recovery and presents the supply curves that were ultimately developed to describe the conservation resource potentially available from T\&D systern efficiency improvements. These supply curves relate the levelized cost of upgrading existing equipment to the estimated amount of energy saved. Stated in this form, the resource represented by $T \& D$ loss reductions can be compared to other regional electrical generation resources (including other conservation possibilities) to determine the most cost-effective method of supplying power to the Pacific Northwest.

Several limitations on the scope of this inquiry were mandated by the availability of adequate information on T\&D systems and utility operations in the Pacific Northwest. First, only energy losses on the systems were estimated. Assessment of the available resource is therefore restricted to a certain degree. (a) Estimates of demand losses (also known as peak losses) for the existing regional T\&D systems were not determined because of the unavailability of critical information, particularly information about the coincidence of utility system peaks with the peaks of individual components of the system.

(a) The omission of demand losses produces a conservative estimate of the resource. However, demand losses are generally considered by the industry to affect capacity in small increments, so that changes in losses will not affect the timing of new facilities, but may affect the size (EPRI 1979). 
Evaluation of losses for underground distribution components was also omitted because of insufficient data. The following four components, whose individual losses constitute the majority of total T\&D losses, were covered in the study:

1. distribution transformers

2. substation transformers

3. prinary feeders

4. transmission facilities (customer-owned).

It should be noted that secondary feeders can also contribute substantially to total losses. However, analysis of conservation options for this component was not undertaken because adequate information was not readily available. Finally, the onty operational modification evaluated involved increasing the voltage on primary feeders from the current operating level of $12.5 \mathrm{kV}$ to $34.5 \mathrm{kV}$. This voltage upgrade option was evaluated primarily to provide information that could be compared with savings achievable by outright component replacenent.

\subsection{ORGANIZATION OF THIS REPORT}

A number of steps were used to develop the supply curves presented in this report. The analytical steps used to assess T\&D loss recovery are highlighted in Figure 1.1. First, the costs associated with the conservation activity were identified. In this study, the assumption was made that some portion of the regional T\&D losses could be recovered if existing equipment is replaced with equipment that operates more efficiently, either by design or because of capacity characteristics. In general, this improvenent in efficiency is associated with an incremental-per-unit cost plus the installation expenses to replace existing equipment. The development of the costs of replacing existing components is described in Section 2.0 of the report.

The next step of the analysis involved estimating the numbers and types of components included in the regional stock of T\&D equipment (distribution transformers, substation transformers, prinary feeders, and customer-owned transinission facilities). This process, which is described in Section 3.0, was carried out using data derived from a survey of BPA customers (Callaway and De Steese 1986). Use of the survey data to establish the operating characteristics of the existing stock is described in Section 4.0. Various methods were used to 


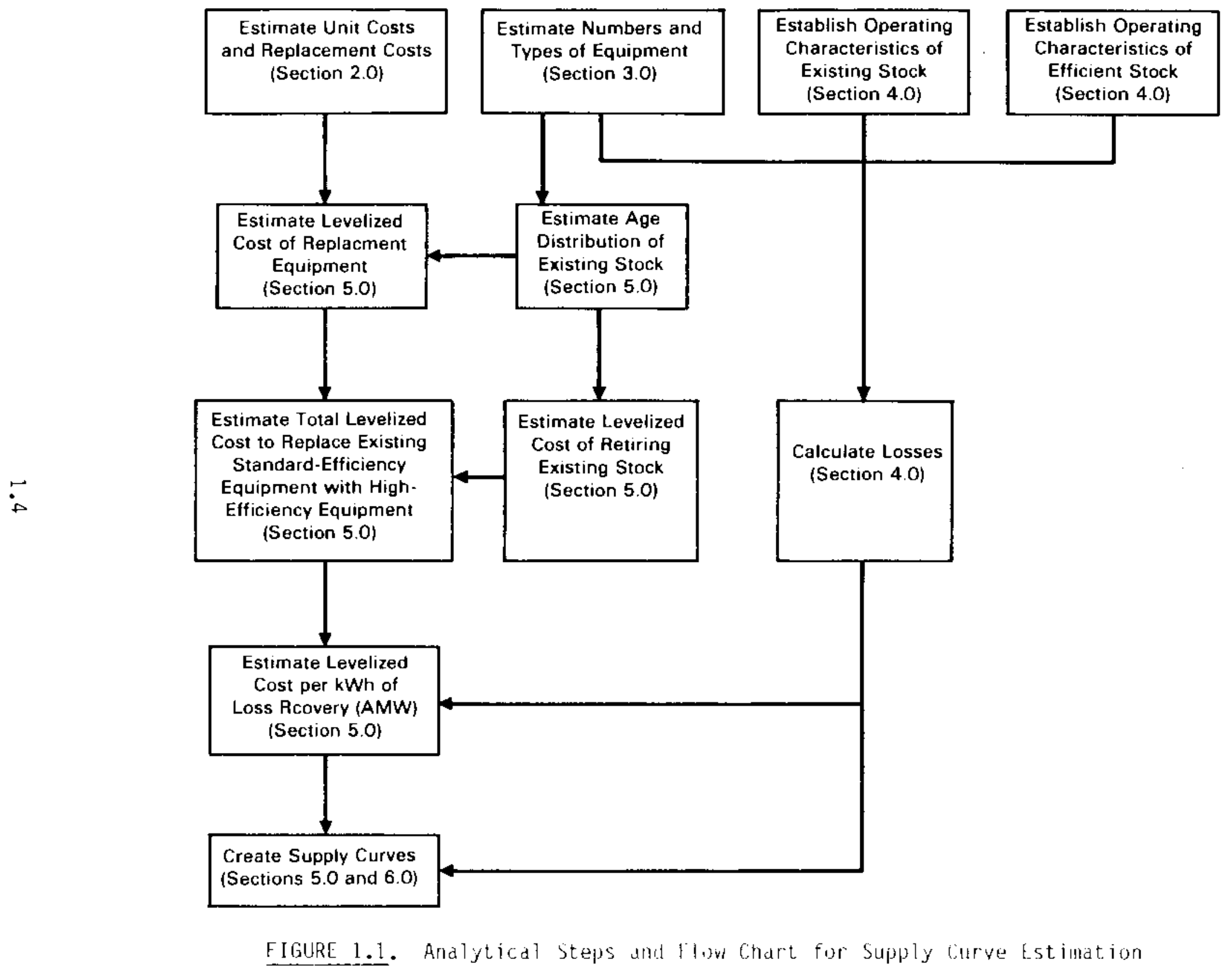


estimate the characteristics of more efficient equipment and to calculate the potential loss recovery available from a region-wide, equipment-replacement effort. These methods are also described in Section 4.0 .

Finally, the potential savings were combined with cost information to create the supply curves. Since differences in the timing of expenses occur in the replacement of equipment, the time value of money and the assumed age of the various components were considered in this process. The methodology developed to consider these factors is described in Section 5.0. The supply curves are displayed and discussed in Section 6.0. Finally, the conclusions are discussed in section 7.0. 


\subsection{EQUIPMENT COSTS}

This section describes the development of cost information about both standard-efficiency equipment and high-efficiency equipment. Cost is a key factor in the development of supply curves for a loss reduction program involving equipment replacement. In this project, accountable costs were considered to be the difference between the costs for replacing standard-efficiency equipment with high-efficiency equipment. Costs associated with the various T\&D equipment are determined mainly by their capacity and performance. Installation costs and other factors affecting costs of standard-efficiency and highefficiency equipment are assumed to be essentially the same.

Specificaliy, conductor prices are a function of installation costs, current carrying capacity, resistance, and material. For transformers, unit costs are functions of installation, design capacity (KVA), load losses, no-load losses, and, at higher capacity levels, the voltage rating. The voltage rating is important in the case of larger transformers such as those used in bulk power or distribution substations. Pole-type and small pad-mounted distribution transformer prices are not as sensitive to changes in voltage rating since their range of applicable ratings is more narrow than those for larger transformers.

\subsection{INFORMATION SOURCES}

The nature of this project required that cost estimates be appropriate for the BPA service area and customers. The large number of utilities included in the study eliminated the possibility of collecting cost estimates that were either utility specific or area specific. Thus, it was necessary to collect information that would result in average costs and prices for the entire area of interest. To ensure that this information was obtained from a broad range of sources, three avenues of research were followed:

- A literature search of published articles, utility work plans, engineering studies, and other information sources was performed. 
- Information was requested frorn utilities both within and outside BPA's service area.

- Information on unit costs and pricing procedures was solicited from equipment manufacturers.

The literature search revealed a number of published articles related to the economic evaluation of loss-reduction measures, technical handbooks that contained some relevant information, and some utility-specific engineering studies. Specific sources of information are listed in the references.

In conjunction with the CSEI Project data base development effort, uti1ities within BPA's service region were interviewed and asked to provide typical or historical costs for procedures such as reconductoring, replacing transformers, and adding capacitors. In addition, cognizant staff at five investorowned utilities located outside of BPA's service area, but within the Pacific Northwest region, were contacted and interviewed by telephone. As a result of these interviews, several engineering studies and one distribution transformer bid sheet were provided to PNL.

A number of distribution-system equipment manufacturers were contacted and asked for pricing information. Onjy two manufacturers agreed to send information.

\subsection{PROBLEMS ENCOUNTERED IN ESTIMATING COSTS}

Technical articles and other published literature proved to be good sources of comparative studies. These sources of information were useful because they usually included a number of design options and economic evaiuations of the options. These economic evaluations provided some insight into the variation of costs with differing design parameters. However, a deficiency existed in virtually all articles of this type; most of the cost information was approximate or even hypothetical, and thus could not be viewed as a reliable estimate of actual costs.

Utility work plans and engineering studies provided more representative information about actual costs. A number of these sources were reviewed and provided a good idea of the general scope of certain costs. However, the work 
plans were similar to the published literature in that they usualiy provided approximate cost data. Normaliy, only one cost estimate was provided rather than a range of costs for various design options. Usually, the design parameters and assumptions were not listed and material and installation costs were seldon separated.

It was originally assumed that the most accurate and reliable cost data would come from manufacturers. However, it was this area of the search for cost information that presented the most problems. Increasing costs of electricity production and the resulting new emphasis on the cost of losses has caused manufacturers to abandon the practice of stocking "standard-design" equipment. Virtually every transformer or capacitor produced is based on a custom design. Thus, it is difficult to identify a standard price list for these components. To quote a price for a particular component, manufacturers require specifications that are too detailed to be developed within the scope of this study. Even if specification of such details was possible, most manufacturers would be unwilling to spend the time and money (e.g., about $\$ 1500$ according to one source) to work through the design process and quote a price that includes efficiency specifications. However, two of the manufacturers contacted did agree to send limited cost information.

Another problem encountered with the limited information received from manufacturers was that price indices are tabulated as a function of the value placed by utilities on the load and no-load losses, rather than as a function of the actual total losses. Therefore, in this study, selection of the levels used for improved-efficiency equipment was somewhat arbitrary. The selections were, however, guided by the data collected fron regional utilities in the technical survey. These data are discussed in Sections 3.0 and 4.0 .

A problem related to all the sources used is that not all prices are quoted in terms of the same base year. Indices from the Handy-Whitman Index of Public Utility Construction Costs (Whitman, Requardt, and Associates 1986) were used in this project to convert the cost data to a comparable form (1980 dollars). However, a discrepancy was noticed between the Handy-Whitman Index and information obtained from one manufacturer. The manufacturer claims that 1984 
transformer prices were identical to 1979 prices, while the Handy-Whitman Index shows an increase in prices of $35 \%$ over the same period.

Finally, typical installation costs for all four T\&D components of interest were difficult to obtain. Often, the total installed cost was quoted with no further breakdown between materials and labor costs. This deficiency made it difficult to distinguish between expense and capital expenditures. Guidance from several regional utilities was used to make estimates of this portion of replacement costs.

\subsection{DATA SUMMARIES}

Since cost data were collected from numerous sources, costs were expressed in terms of dollars from a number of different base years. All costs, with the exception of labor rates, were converted to equivalent 1980 dollars using indices from the Handy-Whitman Index. Labor charges were converted to a 1980 basis using historical base labor rates. Following are descriptions of the data collected and the methods or equations used to estimate costs for each category of component considered in the CSEI Project.

\subsubsection{Conductors}

The typical costs for reconductoring were extracted primarily from utility work plans and engineering studies. From the information provided, it was not possible to separate material and installation costs from total costs in the majority of cases. Material costs were solicited from manufacturers but were not provided. Some information regarding typical installation costs for conductors was received from utilities that responded to the technical survey.

For reconductoring, available data was used in a regression analysis to determine average cost as a function of conductor size. Since many of the data sources provided costs for new construction rather than for reconductoring, a factor was included to make this distinction.

\subsubsection{Distribution Transformers}

Useful information for developing equations that could be used to estimate losses from existing distribution transformers and the cost of replacing the existing transformers with high-efficiency equipment was difficult to obtain. 
Most of the available data was too approximate to be useful. The approximate nature of the data combined with the expectation that design improvements in the last few years may have caused the relationship between cost and losses to vary with time, led to the decision to use data from single bid sheets as the primary information for the regression analyses. As a result, about $95 \%$ of the data used came from the single bid sheets. It was concluded that utilities' bid sheets are the most useful source of information since all the pertinent information and a cross-section of options can be found in one package.

\subsubsection{Substation Transformers}

The cost/loss relationship for larger transformers is more complex than that for distribution transformers. Many factors, such as operating voltage, auxiliary equipment, and cooling apparatus, affect the price of a large transformer. This variability leads to significant differences between cost estimates obtained from various utility work plans and engineering studies.

To calculate the variation in cost resulting from improved efficiency, it was necessary to look at otherwise identical units. Although utility bid sheets would seem to be a good source of information for this purpose, none were acquired. However, general information was provided by respondents to the technical survey. The best indicator of cost was found to be the pricing methodology used by a major equipment manufacturer. This methodology included a cost multiplier based on the level of load losses and no-load losses. The

equation developed on these bases appeared to be a good indicator of how equipment cost varies with efficiency. However, a "typical" level of auxiliaries and options would need to be established if absolute prices are desired.

\subsection{COST EXPRESSIONS}

Analysis of the various sources of cost data produced mathematical expressions that were used to develop cost information for the supply curves. These expressions are described in the following subsections. 


\subsubsection{Conductors}

Losses in distribution lines are a function of the resistance of the conductor. Therefore, to evaluate the economic feasibility of upgrading a segment of conductor, a relationship between current-carrying capacity, resistance, and cost is desired. The functions shown in Table 2.1 were derived from regression analysis to provide necessary information about current-carrying capacity and resistance.

Since wire gauges are usually expressed in terms of American Wire Gauge (AWG) specifications, the following relationship may be used in the conversion to kcmil (thousand circular mils).

$$
k \mathrm{cmil}=0.025(1.12)^{[2(36-a)]}
$$

where AWG Specification Value of a

$\begin{array}{lr}42 & 2 \\ 41 & 1 \\ 1 / 0 & 0 \\ 2 / 0 & -1 \\ 3 / 0 & -2\end{array}$

TABLE 2.1. Functions for Determining Current-Carrying Capacity and Resistance of Conductors

\begin{tabular}{|c|c|c|c|}
\hline \multirow{2}{*}{ Function } & \multirow[b]{2}{*}{ Conductor Type } & \multicolumn{2}{|c|}{$\begin{array}{l}\text { Regression } \\
\text { Coefficients }\end{array}$} \\
\hline & & $\mathrm{a}$ & $\frac{b}{b}$ \\
\hline Ohms $/ m i l e=a+b(k c m i l)^{-1}$ & $\begin{array}{l}\text { Copper } \\
\text { Copperwe ld-Copper } \\
\text { Copperweld } \\
\text { ACSR }\end{array}$ & $\begin{array}{l}0.0076 \\
0.0220 \\
0.0080 \\
0.0039\end{array}$ & $\begin{array}{r}62.65 \\
63.54 \\
59.52 \\
110.81\end{array}$ \\
\hline Capacity (amps) $=a(k c m i l)^{b}$ & $\begin{array}{l}\text { Copper } \\
\text { Copperweld-Copper } \\
\text { Copperweld } \\
\text { ACSR }\end{array}$ & $\begin{array}{l}15.620 \\
14.086 \\
26.150 \\
14.730\end{array}$ & $\begin{array}{l}0.64 \\
0.66 \\
0.61 \\
0.62\end{array}$ \\
\hline Capacity (amps) $=a(0 \mathrm{hms} / \mathrm{mi} 1 \mathrm{e})^{b}$ & $\begin{array}{l}\text { Copper } \\
\text { Copperweld-Copper } \\
\text { Copperweld } \\
\text { ACSR }\end{array}$ & $\begin{array}{l}228.870 \\
236.950 \\
319.420 \\
249.190\end{array}$ & $\begin{array}{l}-0.65 \\
-0.63 \\
-0.61 \\
-0.64\end{array}$ \\
\hline
\end{tabular}


Using the relationships described above, the installed cost of new aluminuin conductor is represented by the following equation:

$$
\$ / m i l e=a+b(k c m i l)+c(x)
$$

where $\mathrm{a}=17,626.90$

$b=30.30$

$c=5,848.7$

$x=1$ for new construction

$=0$ for reconductoring an existing circuit

\subsubsection{Distribution Transformers}

Regression analysis of the available data yielded the following equation that relates unit cost to the level of load and no-load losses.

$$
\$=a+b(k V A)+c\left[(k V A)^{2} /(L L)(N L L)\right]
$$

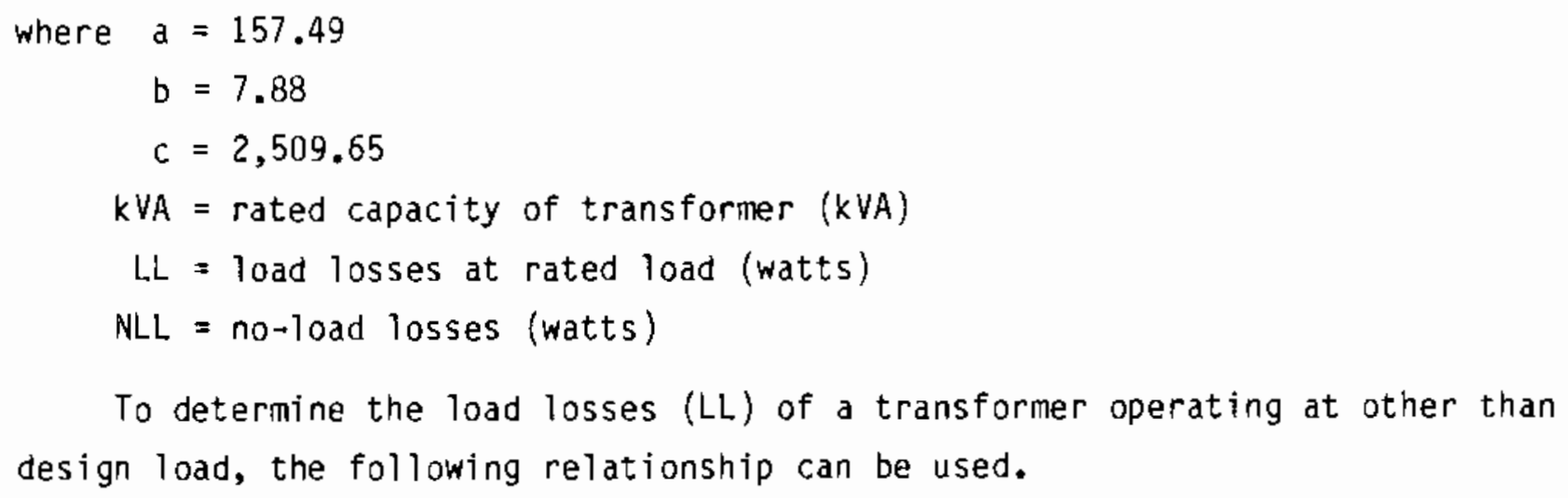

To determine the load losses (LL) of a transformer operating at other than design load, the following relationship can be used.

$$
L L / \text { rated } L L=a+b(\% \text { load })^{2}
$$

$$
\begin{aligned}
\text { where } a & =0.045 \\
b & =0.000098 \\
\% \text { load } & =80 \%<\% \text { load }<200 \%
\end{aligned}
$$




\subsubsection{Substation Transformers}

The following preliminary relations were developed for substation transformer costs. The base cost can be determined using the following relationship:

$$
\$=\left[a(M V A)^{0.75}\right]+\left[b\left(B I L_{k V}\right)^{1.75}\right]
$$

$$
\text { where } \begin{aligned}
a & =19,800 \\
b & =1.55 \\
\text { MVA } & =\text { Installed capacity in MVA } \\
\text { BIL } & =\text { Basic impulse level in } \mathrm{kV}
\end{aligned}
$$

This dollar value is multiplied by an efficiency factor that is based on the level of load and no-load losses. The efficiency factors used in the CSEI supply curve analysis were extracted from a matrix in a manufacturer's price list, which is reproduced in Table 2.2 .

Since the cost valuation of load and no-load losses is determined on a

\begin{tabular}{|c|c|c|c|c|c|c|c|c|}
\hline No-Loed & $55^{\circ} \mathrm{C}$ & $\leq 650$ & $>650<1300$ & $>1300<1950$ & $>1950<2600$ & $>2600<3900$ & $>3900<5200$ & $>5200$ \\
\hline Losses (kw) & $65^{\circ} \mathrm{C}$ & $\leq 500$ & $>500<1000$ & $>1000<1500$ & $>1500<2000$ & $\geq 2000<3000$ & $>3000<4000$ & $>4000$ \\
\hline$<500$ & & 1.00 & 1.04 & 1.07 & 1.10 & 1.16 & 1.24 & 1.32 \\
\hline$>500<1000$ & & 1.04 & 1.06 & 1,08 & 1.11 & 1.17 & 1.25 & 1.33 \\
\hline$>1000<1500$ & & 1.05 & 1.07 & 1.09 & 1.12 & 1.19 & 1.26 & 1.35 \\
\hline$>1500<2000$ & & 1.06 & 1.08 & 1.11 & 1.14 & 1.20 & 1.28 & 1.36 \\
\hline$>2000<2500$ & & 1.08 & 1.10 & 1.12 & 1.15 & 1.21 & 1.29 & 1.37 \\
\hline$>2500<3000$ & & 1.09 & 1.11 & 1.13 & 1.16 & 1.23 & 1.31 & 1.39 \\
\hline$>3000<4000$ & & 1.12 & 1.14 & 1.16 & 1.19 & 1.25 & 1.33 & 1.42 \\
\hline$>4000<5000$ & & 1.15 & 1.16 & 1.19 & 1.22 & 1.28 & 1.36 & 1.42 \\
\hline$>5000$ & & 1.17 & 1.19 & 1.22 & 1.24 & $1.3 i$ & 1.38 & 1.42 \\
\hline
\end{tabular}
case-by-case basis by the utility, the selection of an efficiency factor for the analysis was somewhat arbitrary. To incorporate conservative cost estimates, the highest efficiency factor (1.42) was used in the analysis.

\section{TABLE 2.2 Manufacturer's Efficiency Factors Load Losses ( $\$ / k w)$}




\subsection{NUMBERS AND TYPES OF EXISTING EQUIPMENT}

The numbers and types of existing distribution equipment for the utilities operating in the BPA service area were determined by applying regression analysis to data collected in a survey administered to 144 BPA customers utilities. The results of the survey and the procedures and equations used for estimating equipment quantities and operating characteristics are described in this section. In Section 3.1, the survey that provided the data for the economic analysis and resource estimation is sumarized. A more detailed description of the survey process and a discussion of the responses can be found in a companion CSEI Project report that describes the development of the data base (Callaway and De Steese 1986). The methods used to estimate the total regional stock of the four distribution components are described in Section 3.2. Finaliy, the resulting estimates and conclusions about the estimates and the estimating methodology are discussed in Section 3.3.

\subsection{SUMMARY OF SURVEY RESULTS}

Information on utility distribution system characteristics for utilities in the Pacific Northwest was obtained from a questionnaire that was administered to 144 BPA customers in late 1984. Sixty-seven utilities responded to this survey with either fult or partial responses. The survey questionnaire contained requests for information of a general nature and also for detailed information on system components.

The detailed information about system components provided data on the number and operating characteristics of distribution transformers, distribution substation transformers, primary feeders, and customer-owned transmission lines. Due to a number of factors, including record-keeping practices, staff time and experience, and size of the utility, the quality and completeness of the information received was not uniform. Large utilities with extensive distribution systems usually provided average or sample information on components such as distribution transformers and feeder segments. However, they provided 
more complete and detailed information on substation transformers and transmission facilities. Smaller utilities with computerized record systems often provided very good information on all components. Finally, some small utilities with limited staff and limited records responded by 1) sending hand-recorded, excessively-detailed information that had been prepared for other purposes (e.g., REA feeder voltage drop studies), 2) sending estimated system-average information; or 3) skipping certain component descriptions entirely.

The raw data from the survey questionnaire that was entered in the data base represented the best effort of CSEI project staff to record all available correct information. Estimates of the number of components (by various size categories) in the distribution systems in the region were based on this raw data set. However, when estimating region-wide system inputs for the loss calculations (see Section 4.0), only data that were complete enough to provide adequate information were used.

One exception to the general process of estimating the number and operating characteristics of the components should be noted. Generally only the small proportion of responding utilities that own and operate transmission facilities provided transmission line data. Many of BPA's small municipal customers do not use lines with voltages that exceed primary feeder levels, although varying amounts of 69- and $115-\mathrm{kV}$ subtransmission and transmission lines appear to be common for utilities with geographically extensive service areas. Due to the 1 inited number of utilities with extensive transmission systems, the total mileage of transmission lines (expressed in circuit miles at various voltage levels) was not derived by regression, but from information contained in the Directory of Electric Utilities, 1982-1983 (Electrical World 1983). It was felt that the data from this source provided a more complete and reliable means of estimating the total transmission circuit miles in the region than regression analysis based on the sample data. Information received from the survey was used, however, to estimate the average operating characteristics for transmission lines operating various voltage levels.

Table 3.1 shows the number of utilities that provided information on the various components. It also displays percentages of the estimated regional 
TABLE 3.1. Number of Utilities and Percent of Estimated Total in Sample Data, by Component

\begin{tabular}{|c|c|c|}
\hline Component & No. of Utilities & $\begin{array}{l}\text { Range of Estimated } \\
\text { of Regional Total }\end{array}$ \\
\hline Distribution Transformers & 38 & $22-41$ \\
\hline Primary Feeders & 32 & $15-23$ \\
\hline Substation Transformers & 37 & $8-43$ \\
\hline Transmission & 63 & 100 (as sumed) $^{(b)}$ \\
\hline
\end{tabular}

(a) For example, the number of distribution transformers described by sample data ranged from a low of $22 \%$ of the predicted regional total (<7.5 kVA category) to a high of $41 \%(40-50 \mathrm{kVA}$ category).

(b) Data on transmission lines were reported for 63 of the 144 regional utilities (Electrical World 1983). The combined mileages at each voltage level from this source were assumed to be equal to the regional total.

total (by component category) represented by those data. 0ther pertinent facts about the survey results are discussed by Callaway and De Steese (1986).

\subsection{METHODOLOGY USED TO ESTIMATE NUMBERS AND TYPES OF COMPONENTS}

The analysis to derive supply curves for the resource represented by efficiency improvements required information (i.e., estimates) about both the number and the average operating characteristics of each component in the present regional distribution system. The method used to estimate the totai quantity of components, by size, is discussed in the remainder of this subsection.

\subsubsection{Identification of Component Categories}

Accountability of the wide diversity of sizes and efficiencies of distribution system components existing in the region was accomplished by establishing categories for each of the four components that were examined. The sample records were sorted according to these groupings. Distribution transformers were divided into 11 groups that were based on sizes represented by the capacities specified on their nameplates. The smallest capacity group included 
transformers ranging from 0 to $7.5 \mathrm{kVA}$, and the largest group included transformers larger than $500 \mathrm{kVA}$. Intermediate categories were grouped into what appeared to be fairly natural groupings of kVA ranges. Substation transformers were also grouped into three size categories on the basis of the capacities specified on their nameplates. Primary feeders and transmission lines were grouped by operating voltage levels. The number of categories and the range of values included in each were determined by both the total quantity of records for each component and the capacity/voltage level groupings that were found in the survey data. The specific categories and the size ranges included in each category are shown in Table 3.2 .

TABLE 3.2. Size Categories of Distribution System Components

\begin{tabular}{|c|c|c|}
\hline Component & Category & Size Ranges \\
\hline Distribution Transformers & $\begin{array}{r}7.5 \text { kVA } \\
15.0 \text { kVA } \\
25.0 \text { kVA } \\
40.0 \text { kVA } \\
50.0 \text { kVA } \\
75.0 \text { kVA } \\
100.0 \text { kVA } \\
200.0 \text { kVA } \\
300.0 \text { kVA } \\
500.0 \text { kVA } \\
>500.0 \text { kVA }\end{array}$ & $\begin{array}{r}0-7.5 \mathrm{kVA} \\
7.6-15.0 \mathrm{kVA} \\
15.1-25.0 \mathrm{kVA} \\
25.1-40.0 \mathrm{kVA} \\
40.1-50.0 \mathrm{kVA} \\
50.1-75.0 \mathrm{kVA} \\
75.1-100.0 \mathrm{kVA} \\
100.1-200.0 \mathrm{kVA} \\
200.1-300.0 \mathrm{kVA} \\
300.1-500.0 \mathrm{kVA} \\
\text { over } 500.0 \mathrm{kVA}\end{array}$ \\
\hline Substation Transformers & $\begin{array}{l}\text { Sma I? } \\
\text { Medi um } \\
\text { Large }\end{array}$ & $\begin{array}{r}0-7.5 \text { MVA } \\
7.6-19.9 \text { MVA } \\
\text { over } 20.0 \text { MVA }\end{array}$ \\
\hline Primary Feeders & $\begin{array}{l}\text { One } \\
\text { Two } \\
\text { Three } \\
\text { Four }\end{array}$ & $\begin{array}{r}0-11.9 \mathrm{kV} \\
12.0-17.9 \mathrm{kV} \text { (10w resistance) } \\
12.0-17.9 \mathrm{kV} \text { (high resistance) } \\
18.0-33.0 \mathrm{kV}\end{array}$ \\
\hline Transmission Lines & $\begin{array}{l}\text { Low } \\
\text { Mid } \\
\text { High } \\
\text { Vhigh }\end{array}$ & $\begin{array}{rl}34 & \mathrm{kV} \\
69 \mathrm{kV} \\
115 \mathrm{kV} \\
230 \mathrm{kV}\end{array}$ \\
\hline
\end{tabular}




\subsubsection{Estimation Procedures}

The estimated regional total for each component by size category was obtained by ordinary least squares regression analysis, using the numbers of the utility's consumers in a given sector (residential, commercial, industrial, etc.) as independent variables. This relationship proved to be fairly strong for transformers, but less so for feeder mileage. Service area size and customer density would have been a better independent variable for use in estimating total feeder mileages, but this information was not available for most of the utilities in the region.

The 144 regional utilities were grouped into four categories that were determined by a cluster analysis of size and sectoral sales characteristics (Callaway and De Steese 1986). Although this classification scheme was initially intended to be used for all regressions, it was found to be useful only in those run to predict the number of components in groups whose sizes placed them at the tails of distribution curves. In the prediction of those components in size categories that were more typical and more universally distributed over all utilities in the region, this additional refinement reduced the number of observations that, in turn, jeopardized the strength of the relationship between the independent and dependent variables. Therefore, this additional parameter was subsequently discarded in the regressions run for most size categories of the four components. Table 3.3 displays the regression statistics and the resulting coefficients that were obtained for each component (by category) in this step of the analysis.

The regressions show that there is, as expected, a strong relationship between the number of customers in various sectors and the number of distribution transformers of a given size level. Although the $R^{2}$ value found for the very smallest size group was low (due primarily to the small representation that this size transformer had in the sample), the regressions for the other sizes showed very respectable $R^{2}$ values and strong T-statistics associated with each of the independent variables used. The relationship between numbers of customers and numbers of substation transformers was also reasonably strong in most cases. The number of residential customers proved to be the best predictors of substation transformers in all size categories (although for mixed 
TABLE 3.3. Results of Regressions of Customers Against Quantity of Distribution System Components (95\% confidence level)

\begin{tabular}{|c|c|c|c|}
\hline Component & Equation (a) & $\mathrm{R}^{2}$ & I-Statistic \\
\hline \multicolumn{4}{|c|}{$\begin{array}{l}\text { Distribution Transformers } \\
\text { (by nameplate KVA) }\end{array}$} \\
\hline $\begin{array}{l}0-7.5 \\
7.6-15.0 \\
15.1-25.0 \\
25.1-40.0 \\
40.1-50.0 \\
50.1-75.0 \\
75.1-100.0 \\
100.1-200.0 \\
200.1-300.0 \\
300.1-500.0 \\
>500.1\end{array}$ & $\begin{array}{l}123.7+0.54(\text { IR }) \\
1385+0.13(0)-14.39(0) \\
544.8+0.357(0)-15.38(0) \\
186+0.055(\mathrm{D})-5.71(0) \\
34.1+14.72(0) \\
206.81+0.53(\mathrm{C})-9.72(\mathrm{I}) \\
41.5+0.079(\mathrm{C})-0.94(0) \\
0.14+0.051(\mathrm{C})+0.11(\mathrm{IR})-0.58(0) \\
-0.12+0.57(\mathrm{I}) \\
3.88+0.27(\mathrm{I}) \\
-0.59+0.11(\mathrm{I})+0.16(0)\end{array}$ & $\begin{array}{l}0.33 \\
0.94 \\
0.97 \\
0.96 \\
0.97 \\
0.90 \\
0.96 \\
0.95 \\
0.89 \\
0.85 \\
0.97\end{array}$ & $\begin{array}{l}4.19 \\
21.76,10.90 \\
4.51,13.00 \\
25.51,12.24 \\
32.78 \\
14.76,8.93 \\
25.87,13.09 \\
23.32,3.18,11 \\
17.33 \\
14.49 \\
11.38,21.98\end{array}$ \\
\hline \multicolumn{4}{|c|}{$\begin{array}{l}\text { Substation Transformers } \\
\text { (by nameplate MVA) }\end{array}$} \\
\hline $\begin{array}{l}0-7.5 \\
7.6-19.9(b) \\
7.6-19.9(c)\end{array}$ & $\begin{array}{l}4.50+0.0003(D) \\
0.99+0.00003(I)+.00002(I R) \\
1.70+0.0004(D)-.00006(C)- \\
0.000004(I)\end{array}$ & $\begin{array}{l}0.82 \\
0.36 \\
0.74\end{array}$ & $\begin{array}{l}12.54 \\
2.32,1.74 \\
3.14,3.2,2.14\end{array}$ \\
\hline \multicolumn{4}{|c|}{$\begin{array}{l}\text { Primary Feeders } \\
\text { (by operating kV) }\end{array}$} \\
\hline $\begin{array}{l}0-11.9 \\
12.0-17.9(d) \\
12.0-17.9(e) \\
18.0-50\end{array}$ & $\begin{array}{l}-0.31+.001(D) \\
-33.96+0.68(I R) \\
35.9+0.0002(I) \\
5.59+0.0023(D)+0.07(I R)\end{array}$ & $\begin{array}{l}0.80 \\
0.44 \\
0.35 \\
0.61\end{array}$ & $\begin{array}{l}11.12 \\
4.86 \\
3.98 \\
6.52,2.14\end{array}$ \\
\hline
\end{tabular}

(a) Independent variables are the number of electrical consumers in five sectors: $D=$ domestic; $C=$ commercial; $I=$ industrial; IR = irrigation; $0=$ other.

(b) 7.6-19.9 MVA transformers for small urban and rural utilities and medium sized mixed load utilities (Clusters 1, 2, and 3).

(c) 7.6-19.9 MVA transformers for large and predominantly urban utilities (C)uster 4 ).

(d) $12.0-17.9 \mathrm{kV}$ feeders with low-resistance features.

(e) $12.0-17.9 \mathrm{kV}$ feeders with high-resistance features. 
load and rural utilities, the best predictors appear to be industrial and irrigation customers). Although the coefficients in the equations for substation transformers are quite smal1, spot checks of recent one-line diagrams for utilities that were not included in the survey showed that reasonably good estimates could be obtained using the regression equations. From discussions with $B P A$ staff, it was confirmed that the total number of substation transformers estimated for this analysis coincided with previous BPA estimates of the regional stock.

Although the $R^{2}$ values obtained for the feeder regressions are, on the whole, lower than those for transformers (due to the probable importance of factors other than numbers of customers), relatively strong relationships were found for the largest and smallest size categories of feeders. However, the use of $12.5 \mathrm{kV}$ for primary feeders is a very common practice with many utilities. Not surprisingly, the preponderance (approximately 75\%) of feeders in the sample data were in the middle size category. Since the number of feeders operated at $12.5 \mathrm{kV}$ is more directly related to the size of the service area of the utility than to number of customers, the predictions of the total circuit miles of this size feeder are probably less reliable than the other estimates used in the analysis. However, the regional total of 43,219 circuit miles is close to previous estimates.

\subsection{ESTIMATED NUMBER OF COMPONENTS BY SIZE}

The results of the regression analysis to estimate the total number of distribution system components by size are presented in Table 3.4 The table also includes the estimate of transmission facilities, by circuit mile at various voltages, that were obtained from Electrical World (1983). 
TABLE 3.4. Estimated Number of Components in the BPA Region

\begin{tabular}{|c|c|c|c|}
\hline Component & Category & Component (Wtd. Avg.) (a) & Quantity \\
\hline $\begin{array}{l}\text { Distribution } \\
\text { Transformers }\end{array}$ & $\begin{array}{l}0-7.5 \text { (kVA) } \\
7.5-15.0 \\
15.1-25.0 \\
25.1-40.0 \\
40.1-50.0 \\
50.1-75.0 \\
75.1-100.0 \\
100.1-200.0 \\
200.1-300.0 \\
300.1-500.0 \\
>500\end{array}$ & $\begin{array}{l}5 \text { (kVA) } \\
10 \\
15 \\
28 \\
48 \\
52 \\
75 \\
118 \\
232 \\
305 \\
1032\end{array}$ & $\begin{array}{c}44,664(b) \\
435,204 \\
331,274 \\
135,557 \\
173,401 \\
118,531 \\
24,656 \\
18,454 \\
6,384 \\
3,501 \\
3,019\end{array}$ \\
\hline $\begin{array}{l}\text { Substation } \\
\text { Transformers }\end{array}$ & $\begin{array}{l}0-7.5 \text { (MVA) } \\
7.6-20 \\
>20\end{array}$ & $\begin{array}{r}5.727 \text { (MVA) } \\
11.069 \\
56.023\end{array}$ & $\begin{array}{l}789(b) \\
168 \\
238\end{array}$ \\
\hline Primary Feeders & $\begin{array}{l}0-11.9(\mathrm{kV}) \\
12.0-17.9 \\
18.0-50\end{array}$ & $\begin{array}{r}7.0(\mathrm{kV}) \\
12.6 \\
24.8\end{array}$ & $\begin{array}{l}3,508(c) \\
43,219 \\
11,933\end{array}$ \\
\hline Transmission & $\begin{array}{l}34.5(k V) \\
69 \\
115 \\
230\end{array}$ & $\begin{array}{r}34.5(\mathrm{kV}) \\
6.9 \\
11.5 \\
23.0\end{array}$ & $\begin{array}{c}4,603(c) \\
4,254 \\
12,080 \\
4,161\end{array}$ \\
\hline
\end{tabular}

(a) In the loss calculations, a weighted average of the kVA, MVA or $k V$ of all the sample components in a given size category was used. In other words, the weighted average KVA of sample transformers in the 0-7.5 kVA category was $5 \mathrm{kVA}$; this value was used in the calculation of losses for that group.

(b) Number of transformers in each size group.

(c) Conduct or circuit miles. 


\subsection{DETERMINATION OF LOSSES AND OPERATING CHARACTERISTICS}

In this section, estimated losses and loss recovery for the four main distribution system components are discussed. A brief general discussion of loss calculation methodologies is provided first and is followed by a detalled discussion about the derivation of loss estimates for each component. Conclusions concerning the loss estimates that were used for the supply curve calculations complete the section.

The per-unit loss leveis of existing equipment were estimated using component data collected in the survey as described in Section 3.0. Assumptions used in making the estimates were derived from literature on distribution system loss calculations, from previous regional level studies, and from studies conducted on regional utility systems. Losses for more efficient replacement equipment were also estimated, using values provided by several methods as described in the following subsection. The per-unit savings attributable to the potential loss reductions, multiplied by the number of components reported in Section 3.0, provided the predicted annual regional savings that were incorporated into the supply curve calculations.

Section 4.1 very generally discusses loss assessment methodologies and Section 4.2 provides background information about distribution system losses. Section 4.3 contains a discussion of the assumptions that were utilized in the loss estimations for each component. In Section 4.4, the operating characteristics of the four components derived from the survey data and the literature review are discussed. Finally, the calculation of the losses for each component is covered in Section 4.5 .

\subsection{LOSS ESTIMATION METHODOLOGIES}

Four approaches to distribution system loss calculation were identified and evaluated to determine their suitability for use in this study.

1. The method described in the BPA Distribution System Efficiency Handbook (BPA 1981).

2. The SCALE code (EPRI 1983). 
3. The detailed calculation of distribution losses (EPRI 1983).

4. The DSAS method (Sun et a1. 1980).

A summary of these approaches and the evaluation process is presented in Appendix A. A principal difficulty in adapting a system-specific loss estimating methodology to the task of assessing region-wide losses is that the data collection effort is proportional to the number of representative system descriptions needed. Based on the information requirements, the complexity of the calculations, and the modifications necessary to represent a regional system composed of many separate utility systems, the detailed approaches deve1oped by the Electric Power Research Institute (EPRI 1983) and also by the Energy Systems Research Center of the University of Texas (Sun et al. 1980) were not attempted. The first and second approaches, developed by BPA (1981) and by westinghouse for EPRI (EPRI 1983), were also more appropriate for calculating losses of individual components in a single system rather than in a region-wide system, but their data requirements were such that it was possible use them in developing the compromise methodology used in this CSEI study.

\subsection{BACKGROUND: T\&D SYSTEM LOSSES}

Transmissions and distribution system losses as defined in this study were considered to be the difference between the average annual power requirements of each utility and its annual sales (including self use). On the average, utilities in the BPA region "lose" approximately $8 \%$ of their power requirements. These losses occur for a number of reasons: 1) electrical impedance of system components, 2) faulty metering, 3) accounting practices, 4) billing errors, and 5) theft. The CSEI study addressed only losses related to the inherent operating efficiency of utility I\&D systems. Since a number of BPA customers generate electricity and transmit it over varying distances to consumption points, the study also includes the losses of non-BPA owned transmission facilities.

Power system losses can be viewed as having two components: 1) demand (also termed capacity) losses and 2) energy losses. Demand losses, which occur at the time of system peaks, increase generating capacity requirements. Energy 
losses require additional energy to be supplied to meet the system loads (EPRI 1983). Because of the difficulty in determining critical peak data on the various distribution systems and the size and coincidence of component peaks within each system, the CSEI study was limited to the analysis of energy loss reduction.

Energy losses can occur on all components of a distribution system, but studies have shown that the principal sources are the primary conductors and distribution transformers. (Customer-owned transmission facilities, which are not usually considered part of a "distribution system," are included in the CSEI study because they are also a substantial source of losses.) Conductor loss occurs primarily because of the resistance of the conducting materials (copper and aluminum) to the flow of electric current. In general, the smaller the diameter of the conductor, the greater the resistance to the flow of electrical current. When distribution systems are constructed, utilities generally attempt to achieve an economic balance between the cost of larger conductors and the cost of the losses that are expected to occur as conductor size decreases. The voltage at which a distribution or transmission conductor is operated also affects the level of losses. To supply a given load, the current required is inversely proportional to the voltage and line losses are proportional to the square of the current.

Transformers generate losses in two ways. Coil loss is caused by the impedance to the flow of current in the transformer windings when supplying an electrical load. This loss, which is also known as copper loss, is called the load loss. The second source of loss results from hysteresis and eddy currents in the steel core of the transformer, which are independent of the load. This loss is referred to as core loss, or no-load loss.

\subsection{ASSUMPTIONS}

Much of the information required to estimate the losses from existing equipment was available from the survey data. However, certain parameters had to be assumed by using 1) values described in the literature or 2) in some cases, reasonable estimates based on other loss studies. The assumptions that were used are identified and discussed in the following subsections. 


\subsubsection{Distribution Transformers}

The nameplate load loss and no-load loss values (in watts) for the transformer sizes evaluated in this study were obtained by regressing known average values for load and no-load losses for standard- and high-efficiency transformers against transforner nameplate capacity, which ranged from $5 \mathrm{kVA}$ to 5000 KVA (BPA 1981). (a) The resulting equations were:

$$
\begin{aligned}
\text { Standard Load Loss }(w) & =-608.3+350.1 \log _{\mathrm{e}} \text { (capacity) } \\
\text { Standard No-Load Loss }(W) & =-172.7+106.3 \log _{\mathrm{e}} \text { (capacity) } \\
\text { High-Efficiency Load Loss }(W) & =-296.3+197.9 \log _{\mathrm{e}} \text { (capacity) } \\
\text { High-Efficiency No-Load Loss }(W) & =-99.3+65.4 \log _{\mathrm{e}} \text { (capacity) }
\end{aligned}
$$

These regression equations were then used to obtain load loss and no-load loss estimates for the sample transformers.

The transformer load factor was also unknown. This parameter, which is the average load of a component (or system) per unit of peak load, is necessary when calculating loss factor, an element in the transformer loss equation. Using an estimated regional average transformer load factor of 0.4 , the loss factor was calculated using the following relationship

$$
L S F=\left(A \times L D F^{2}\right)+(1-A) L D F
$$

where $L S F=$ the loss factor

$A=$ constant used by the industry (typical value is 0.85 )

$L D F=$ the load factor, defined as the ratio of average annual load to peak load, per unit.

(a) Standard-efficiency transformers had an overall efficiency of $97.8 \%$; highefficiency transformers achieved an efficiency level of $98.4 \%$. 
In the loss calculation for distribution transformers, a predominance of standard-efficiency transformers among existing equipment was assumed. However, according to information obtained from the CSEI survey and phone conversations with utility engineers and BPA personnel it is quite likely that many transformers installed in recent years are of the high-efficiency type.

\subsubsection{Substation Transformers}

Detailed and presumably reliable information on substation transformers from the survey data provided most of the parameters necessary for estimating losses from this component. (a) The value of the loss-factor coefficient (A) was again assumed to be 0.85 , but the load factor $(0.6)$ used in the calculation was obtained from survey data. The basic impulse level required to estimate the cost of both standard-efficiency and high-efficiency equipment was obtained from current industry catalogs.

\subsubsection{Primary Feeders}

The calculation of feeder energy losses was done in two stages. An assumed distribution factor $(0.765)$, which was based on national averages reported in the literature, was used for calculating feeder losses. In addition, conductor size and resistance values for aluminum conductor (operating at $50^{\circ} \mathrm{C}$ and carrying current at approximately $75 \%$ capacity) from the Standard Handbook for Electrical Engineers (1978) were used to calculate the difference in $\mathrm{I}^{2} \mathrm{R}$ losses between the existing conductor size categories and conductors that are three sizes larger.

\subsubsection{Iransmission Lines}

Literature-derived values for conductor resistance were aiso used to calculate transmission-line losses. A distribution factor of 1.0 was assumed for these calculations.

(a) While some of the utilities that responded had incomplete records for certain transmission and distribution system components, in general all had good records of size, number, and performance for substation transformers. It is likely that this is due to the small numbers of transformers involved when compared to the large quantities of distribution transformers. Most BPA customers have only 10 to 30 substation transformers. 


\subsection{OPERATING CHARACTERISTICS OF EXISTING EQUIPMENT ANO MORE EFFICIENT EQUIPMENT}

The size categories and estimated operating features of each component are provided in Tables 4.1 through 4.4. Discussions of how the operating characteristics were derived are presented in subsequent subsections. The relative accuracy of these characteristics depends on a number of factors including the accuracy of the sample data, the representativeness of data, and the effect of using values derived from weighted-sample averages and certain literaturederived assumptions. Not all of these factors can be controlled or are known. Therefore, the values in the tables shouid be viewed as representative of the likely features of regional distribution system components. A higher level of confidence in this estimate would be possible with a statistical (i.e., probability) sample based on an appropriate sample design and adequate utility response. However, the CSEI Project survey (Callaway and De Steese 1986) indicated that obtaining full and accurate characterization of many elements in a given sample frame might be difficult because many regional utilities do not have component data at the required level of detail. While this problem could be overcome statistically, the cost of a more detailed survey is probabiy the greatest barrier to obtaining better data.

\subsubsection{Distribution Transformer Characteristics}

The operating characteristics for distribution transformers reported by each utility that responded to the survey were typically the average for a given transformer size group. The parameters used in the loss calculations for the existing component capacities and peaks (Table 4.1) were determined by computing categorical averages of those data that were weighted by the number of transformers reported by each utility in each size group.

As noted above, the load losses and no-load losses shown in Table 4.1 were derived by regression equations using data from the literature, since very few utilities reported these data. One possible effect of the use of these derived values should be noted. The equations used to estimate standard-efficiency and high-efficiency equipment load losses were derived from representative values for transformers operating at peak loads that equaled the ratings specified on 
TABLE 4.1. Distribution Transformers: Categories and Estimated Operating Characteristics of Regional Stock

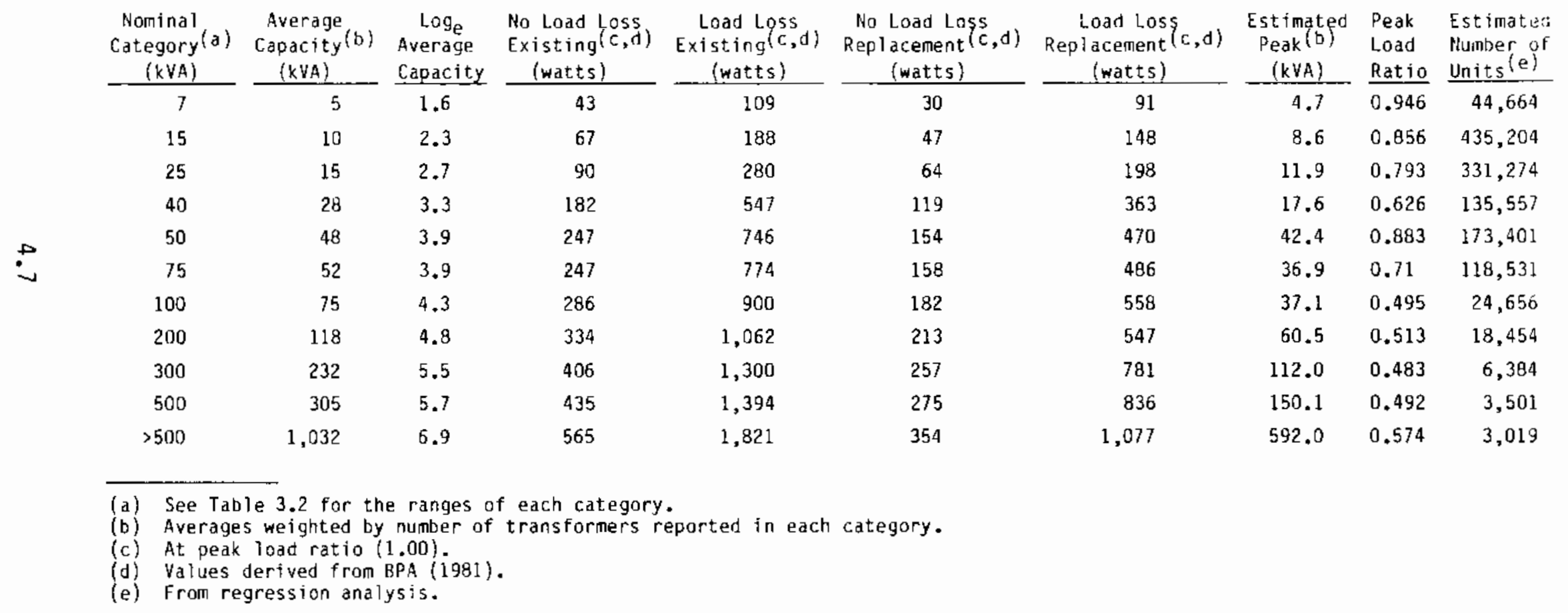


TABLE 4.2. Substation Transformers: Categories and Operating Characteristics

\begin{tabular}{|c|c|c|c|c|c|c|c|c|}
\hline & Average & No Load & & No & & & & \\
\hline $\begin{array}{c}\text { Category } \\
\text { (kVA) }\end{array}$ & $\begin{array}{c}\text { Installed } \\
\text { Capacity } \\
(\mathrm{k} \vee \mathrm{a})\end{array}$ & $\begin{array}{c}\text { Loss } \\
\text { Existing } \\
(\mathrm{kH})(\mathrm{b})\end{array}$ & $\begin{array}{l}\text { Load Loss } \\
\text { Existing } \\
(\mathrm{kW})(\mathrm{b})\end{array}$ & $\begin{array}{l}\text { Load Loss } \\
\text { Replacement } \\
(\mathrm{kW})(\mathrm{c})\end{array}$ & $\begin{array}{l}\text { Load Loss } \\
\text { Replacement } \\
(\mathrm{kw})(\mathrm{c})\end{array}$ & $\begin{array}{l}\text { Average } \\
\text { Peak } \\
(x \vee A)(b)\end{array}$ & $\begin{array}{l}\text { Peak } \\
\text { Load } \\
\text { Ratio (d) }\end{array}$ & $\begin{array}{l}\text { Estimated } \\
\text { Number of } \\
\text { Units }(e)\end{array}$ \\
\hline 7,500 & 5,727 & 10.6 & 39.0 & 7.2 & 25.8 & 3,038 & 0.53 & 789 \\
\hline
\end{tabular}

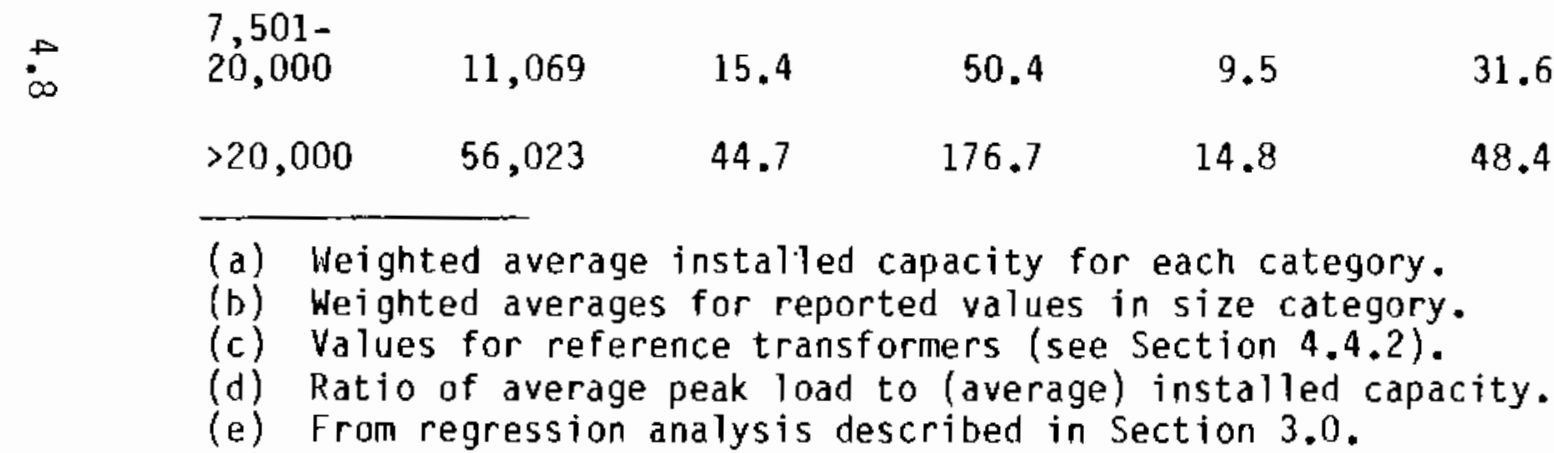


TABLE 4.3a. Primary Feeders: Operating Characteristics of Sample Data(a)

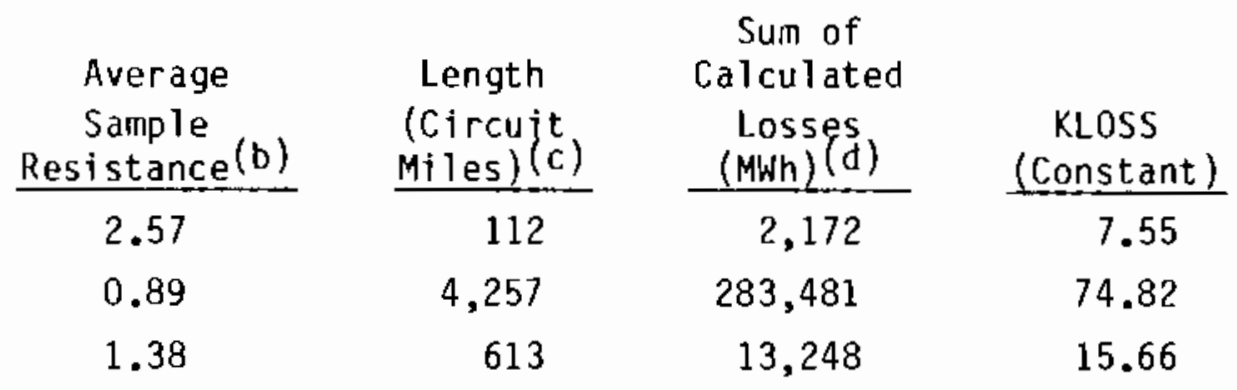

TABLE 4.3b. Primary Feeders: Categories and Estimated 0perating Characteristics of Regional Stock

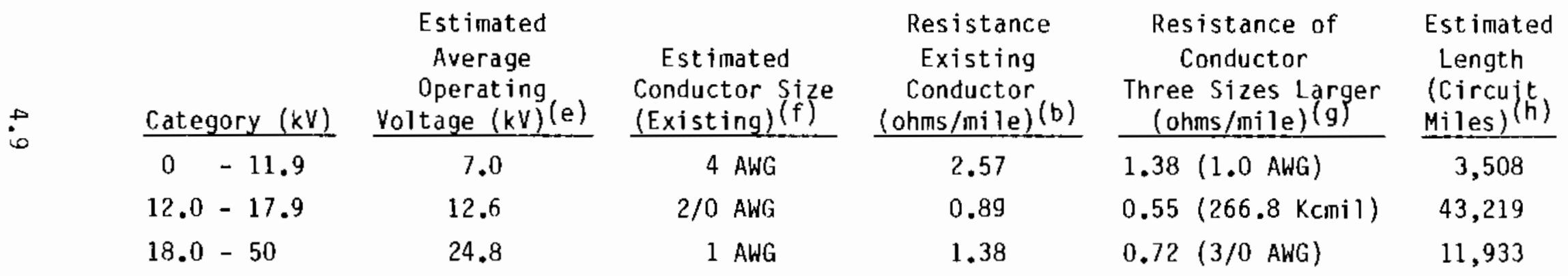

(a) Table 4.3a data were used to compute a constant (KLOSS), which was then used in the actual loss calculations performed with data from Table $4.3 b$ (see text).

(b) Real ACSR resistance closest to weighted average of feeder resistances reported by utilities (Standard Handbook for Electrical Engineers 1978).

(c) Sum of reported circuit miles of ali sample feeders in each category.

(d) Losses calculated for each feeder/feeder segment using equations described in the text.

(e) Weighted average of sample data.

(f) The ACSR conductor size with average sample resistance [see footnote (b) above].

(g) Standard Handbook for Electrical Engineers 1978; CRC Handbook 1981.

(h) Regional totals estimated by regression (Section 3.0 ). 
TABLE 4.4a. Transmission Lines: Operating Characteristics of Sample Data(a)

\begin{tabular}{|c|c|c|c|c|c|}
\hline $\begin{array}{c}\text { Categories } \\
(\text { Operating kV })\end{array}$ & $\begin{array}{c}\text { Average Sample } \\
\text { Resistance } \\
\text { (ohms/mile)(b) }\end{array}$ & $\begin{array}{c}\text { Assumed } \\
\text { Conductor }(c) \\
\text { Size } \\
\end{array}$ & $\begin{array}{l}\text { Length } \\
\text { (circujt } \\
\text { miles) (d) }\end{array}$ & $\begin{array}{c}\text { Sum of } \\
\text { Calculated } \\
\text { Losses } \\
\text { (Mwh) }(\mathrm{e}) \\
\end{array}$ & $\begin{array}{c}\text { KLOSS } \\
\text { (constant) }\end{array}$ \\
\hline Low $(34.5)$ & 0.895 & $2 / 0 A W G$ & 461.2 & 1,902 & 4.61 \\
\hline Med (69) & 0.895 & $2 / 0$ AWG & 806.8 & 12,836 & 17.78 \\
\hline $\mathrm{Hi}(115)$ & 0.306 & $336.4 \mathrm{Kcmil}$ & 555.1 & 39,123 & 230.37 \\
\hline $\mathrm{VHi}(230)$ & 0.123 & $874.5 \mathrm{Kcmi} 1$ & 456.8 & 65,624 & $1,167.46$ \\
\hline
\end{tabular}

TABLE 4.4b. Transmission Lines: Categories and Estimated Operating Characteristics of Regional Stock

\begin{tabular}{|c|c|c|c|c|c|}
\hline 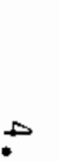 & $\begin{array}{r}\text { Operating } \\
\text { Voltage (kv) }(f) \\
\end{array}$ & $\begin{array}{l}\text { Assumed } \\
\text { Conductor } \\
\text { Size (c) }\end{array}$ & $\begin{array}{c}\text { Resistance } \\
\text { Existing } \\
\text { Conductor(b) } \\
\end{array}$ & $\begin{array}{l}\text { Resistance of } \\
\text { Conductor Three } \\
\text { Sizes Larger }(g)\end{array}$ & $\begin{array}{l}\text { Length } \\
\text { (circujt } \\
\text { miles) }(h) \\
\end{array}$ \\
\hline \multirow[t]{4}{*}{ 号 } & 34.5 & $2 / D$ AWG & 0.895 & $0.385(266.8 \mathrm{Kcmil})$ & 4,603 \\
\hline & 69 & $2 / 0$ AWG & 0.895 & $0.385(266.8 \mathrm{Kcmil})$ & 4,254 \\
\hline & 115 & $336.4 \mathrm{Kcmil}$ & 0.306 & $0.206(500 \mathrm{Kcmil})$ & 12,080 \\
\hline & 230 & $874.5 \mathrm{Kcmil}$ & 0.123 & $0.104(1033.5 \mathrm{Kcmil})$ & 4,161 \\
\hline
\end{tabular}

(a) Table 4.4a data were used to compute a constant (KLOSS), which was then used in the actual loss calculations performed with data from Table 4.4b (see text).

(b) Real ACSR resistance closest to weighted average of transmission resistances reported by utilities (Standard Handbook for Electric Engineers 1978).

(c) ACSR conductor size with average sample resistance [see footnote (b) above].

(d) Sun of reported circuit miles of all sample transmission lines in each category.

(e) Losses calculated by equations in the text.

(f) Standard transmission operating voltages.

(g) Standard Handbook for Electrical Engineers (1978); CRC Handbook (1981).

(h) Electrical World (1983). 
their nameplates. The peak load ratio, defined as the peak ioad divided by rated capacity, directly affects the level of load losses. However, almost a?l of the average peak-load ratios calculated for BPA customer transformers from available CSEI survey data (Callaway and De Steese 1986) were less than 1.0. In other words, many transformers (particularly substation transformers) are currently estimated to be carrying peak loads that are below their design capacity. (This apparent under-utilization phenomenon was also noted for other components.) If, on the average, regional peak-load ratios for distribution transformers are also typically below 1.0, the predicted losses (see Section 4.5) are probably slightly overstated for both the existing standardefficiency equipment units and the high-efficiency replacement equipment. Table 4.1 contains the estimated operating characteristics for distribution transformers. The effect of using oversized distribution system components is discussed further in Section 6.0 .

\subsubsection{Substation Transformers}

Substation transformers are custom-built to comply with efficiency and cost specifications stated by the utility, so no reference efficiency exists that can be used as a hypothetical "more efficient" replacement transformer. Potential loss reductions for these components, therefore, were estimated by a different technique. The efficiency of each transformer reported in the survey was computed as follows:

$$
E=\frac{A-(N L L+L L)}{A} \times 100
$$

where $E=$ the efficiency of the unit $(\%)$

$A=$ installed nameplate capacity of the unit (kVA)

NLL = the nameplate no-Toad loss of the unit $(\mathrm{kW})$

$\mathrm{LL}=$ the nameplate load loss of the unit $(\mathrm{kW})$.

In each size group (small, medium, or large) reported in the survey, the transformer with the highest efficiency rating was selected as the "reference" transformer. The nameplate load and no-load loss values for the reference 
transformer (scaled by the proportion of the group's average installed capacity to the reference transformer installed capacity) were used as the load and noload loss values of the replacement transformer for that group. Substation transformer characteristics are shown in Table 4.2.

\subsubsection{Primary Feeders and Transmission Lines}

A large variety of conductor materials and resistances were reported in the sample data for feeder and transmission lines. In order to get representative values for conductor resistance, the $I^{2} R$ resistances for each size group were averaged (i.e., weighted by the circuit miles of each segment reported). This group average was converted to a "real" resistance value using Table 4.32 in the Standard Handbook for Electrical Engineers (1978). The handbook resis tance for ACSR conductor that was closest to the reported group average was selected, and the conductor size corresponding to that resistance was used as the category's "base" or "representative" conductor for the loss calculations. The replacement conductor was also ACSR, but of a gauge three sizes larger than that of the "base" wire. For example, the weighted average resistance for medium size $12.5 \mathrm{kV}$ feeders was close to 0.89 ohms/mile, the "real" resistance for $2 / 0$ AWG ACSR conductor. To reduce losses, this conductor was hypotheticaliy "replaced" in the calculations with wire that was 3 sizes larger $(266.8 \mathrm{Kcmi1})$, which has a resistance of 0.552 ohms $/ \mathrm{mile}$ when operating at $50^{\circ} \mathrm{C}$ and $60 \mathrm{HZ}$ (Standard Handbook for Electrical Engineers 1978). The resistance of the selected replacement line for each size group was used to calculate the losses of the replacement conductor for feeders and transmission lines. Operating characteristics estimated for primary feeders are shown in Table 4.3, and those for transmission lines in Table 4.4 .

\subsection{ESTIMATED PER UNIT LOSSES FOR EXISTING AND REPLACEMENT COMPONENTS}

The annual energy losses estimated to occur on a per unit basis for each component by size category are shown in Table 4.5. The equations used to calculate these values are described below. 
TABLE 4.5. Estimated Annual Energy Losses (per unit) and Loss Recovery

\begin{tabular}{|c|c|c|c|c|}
\hline Component & Size Category & $\begin{array}{l}\text { Per Unit } \\
\text { Losses } \\
\text { Existing } \\
\end{array}$ & $\begin{array}{c}\text { Per Unit } \\
\text { Replacement } \\
\end{array}$ & Savings \\
\hline $\begin{array}{l}\text { Distribution } \\
\text { Transformers }\end{array}$ & $\begin{array}{l}0-7.5(\mathrm{kVA}) \\
7.6-15.0 \\
15.1-25.0 \\
25.1-40.0 \\
40.1-50.0 \\
50.1-75.0 \\
75.1-100.0 \\
100.1-200.0 \\
200.1-300.0 \\
300.1-500.0 \\
>500\end{array}$ & $\begin{array}{r}544(k W h) \\
823 \\
1090 \\
1962 \\
3092 \\
2833 \\
2834 \\
3405 \\
4077 \\
4389 \\
5979\end{array}$ & $\begin{array}{rl}402 & (\mathrm{kWh}) \\
597 & \\
774 & \\
1286 & \\
1978 & \\
1804 & \\
1829 & \\
2158 & 2564 \\
2756 & \\
3710 & \end{array}$ & $\begin{array}{r}142(\mathrm{kWh}) \\
226 \\
316 \\
676 \\
1114 \\
1029 \\
1005 \\
1247 \\
1513 \\
1633 \\
2269\end{array}$ \\
\hline $\begin{array}{l}\text { Substation } \\
\text { Transformers }\end{array}$ & $\begin{aligned} & 0-7.5 \text { (MVA) } \\
& 7.6-19.9 \\
> & 20\end{aligned}$ & $\begin{array}{l}131 \text { (Mwh) } \\
207 \\
834\end{array}$ & $\begin{array}{r}88 \text { (MWh) } \\
128 \\
250\end{array}$ & $\begin{array}{r}43 \text { (Mwh) } \\
79 \\
584\end{array}$ \\
\hline $\begin{array}{l}\text { Primary } \\
\text { Feeders }\end{array}$ & $\begin{array}{l}0-11.9(\mathrm{kV}) \\
12.0-17.9^{-9}\end{array}$ & $\begin{array}{l}14.8 \text { (MWh) } \\
50.9\end{array}$ & $\begin{array}{r}7.8(\mathrm{MWh}) \\
31.4\end{array}$ & $\begin{array}{r}7.0(\mathrm{MWh}) \\
19.5\end{array}$ \\
\hline $\begin{array}{l}\text { Transmission } \\
\text { Lines }\end{array}$ & $\begin{array}{l}34.5(\mathrm{kV}) \\
69 \\
115 \\
230\end{array}$ & $\begin{array}{r}41.2 \text { (MWh) } \\
15.9 \\
70.5 \\
143.7\end{array}$ & $\begin{array}{r}17.7 \text { (MWh) } \\
6.8 \\
47.4 \\
121.1\end{array}$ & $\begin{array}{r}23.5(\mathrm{MWh}) \\
9.1 \\
23.1 \\
22.6\end{array}$ \\
\hline
\end{tabular}

\subsubsection{Transformer Losses}

The following equation, which was developed by Westinghouse for EPRI (1983), was used for calculating transformer losses.

$$
L T=8.76\left[N L L+L L\left(P L R^{2}\right)(L S F)\right]
$$

where $L T$ = annual loss in kWh per year (per transformer for distribution transformers), MWh for substation transformers

$\mathrm{NLL}=$ no load loss, watts or $\mathrm{kW}$ (for substation transformers)

$L L=$ load loss, watts or $\mathrm{kW}$

$P L R=$ peak load ratio (ratio of peak $k V A$ to rated $k V A$ )

LSF = loss factor. 
A standard loss estimation methodology was used to calculate feeder and transmission line losses from the sample data. To simplify the final loss estimate for the regional stock, however, the survey data (including the per mile annual losses calculated for each size category) were used to create a set of constants (KLOSS) to account for certain parameters in the original equation whose values remained constant within a given size category.

The following equation was used to calculate losses for each sample feeder or transmission segment:

$$
L_{L}=\frac{8.76\left(p^{2}\right)(r)(L S F)(L)}{(k V)^{2}}
$$

where $L_{L}=$ line losses in kwh per year per circuit mile (overhead feeder); or MWh per year per circuit mile (transmission lines)

$\mathrm{p}=$ peak apparent power in $\mathrm{kVA}$

$r$ = resistance conductor in ohms per mile (using reported resistance) $L S F=$ loss factor

$L=$ transmission line or feeder length in circuit miles $k V=$ voltage in $k V$.

The sum of the losses for all feeder/transmission line segments in each size group of feeder or transmission line in the sample data base were then represented as the product of a constant average-group resistance and the sum of the feeder lengths:

$$
\operatorname{SUMLOSS}_{n}=\left(\operatorname{KLOSS}_{n}\right)\left(\operatorname{RR}_{n}\right)\left(\operatorname{TLEN}_{n}\right)
$$

where SUMLOSS $_{n}=$ sum of the calculated losses for sample lines, in MWh per year for size group $n$

$$
\text { KLOSS }_{n}=\text { constant for size group } n
$$

$R R_{n}=$ "real" resistance closest to size group $n$ average resistance TLEN $_{n}=$ total reported length of line in size group $n$, circuit miles. 
Solving for KLOSS $n$ in the preceding equation results in the following expression:

$$
\operatorname{KLOSS}_{n}=\frac{\text { SUMLOSS }_{n}}{\left(\operatorname{RR}_{n}\right)\left(\operatorname{TLEN} N_{n}\right)}
$$

The following equation was then used to calculate the loss estimate for the regional stock:

$$
\operatorname{LOSS}_{n}=\left(R R_{n}\right)\left(\operatorname{KLOSS}_{n}\right)(D F)
$$

where LOSS $_{n}=$ loss per circuit mile of line in MWh per year for size group $n$ $D F=$ distribution factor $(0.765$ for feeders, 1.0 for transmission lines)

All of the losses were calculated on a per unit basis for components at the estimated existing operating characteristics and for the replacement components that were more efficient because of size or design. The per unit annual savings (see Table 4.5) were then used to calculate a supply curve for each component, as described in Section 5.0. 


\subsection{DEVELOPMENT OF SUPPLY CURVES}

Once the cost and energy savings were estimated for both standardefficiency and high-efficiency equipment, supply curves could be developed. The supply curves relate the cost associated with recovering losses to those recovered losses. Basically, the energy saved from high-efficiency equipment was costed as the difference between purchasing and installing more efficient equipment and the costs that would be incurred if the use of standardefficiency equipment continued.

More efficient equipment can be used to replace worn out standardefficiency equipment, or it can be installed to replace currently operating standard equipment that is still in good condition. In the second case, there is a difference in the timing of when the costs (of early replacement as compared with normal replacement) are incurred. Therefore, the time value of money should be considered in the development of supply curves.

After the required data was collected, estimating the supply curves involved three steps. The steps involved are shown in the flow diagram in Figure 5.1, which is derived from Figure 1.1 to show these input steps. First, the vintages of existing equipment were estimated so that differences in the timing of costs could be considered. Second, the added cost per year of replacing existing equipment with more efficient equipment was calculated. Finally, the energy savings corresponding to loss reductions from using more efficient equipment were estimated. After these three steps were completed, the information was then combined into individual supply curves for each component. The total resource available to the region from distribution equipment replacement at various levels of costs was also provided by combining these separate supply curves into a single curve.

\subsection{VINTAGES OF EXISTING EQUIPMENT}

To determine the effect on the costs of the difference in the timing caused by early replacement of equipment, normal replacement times were estimated. If it is assumed that all equipment of a certain type has the same rated lifetime, then only the age of present equipment needs to be determined. 


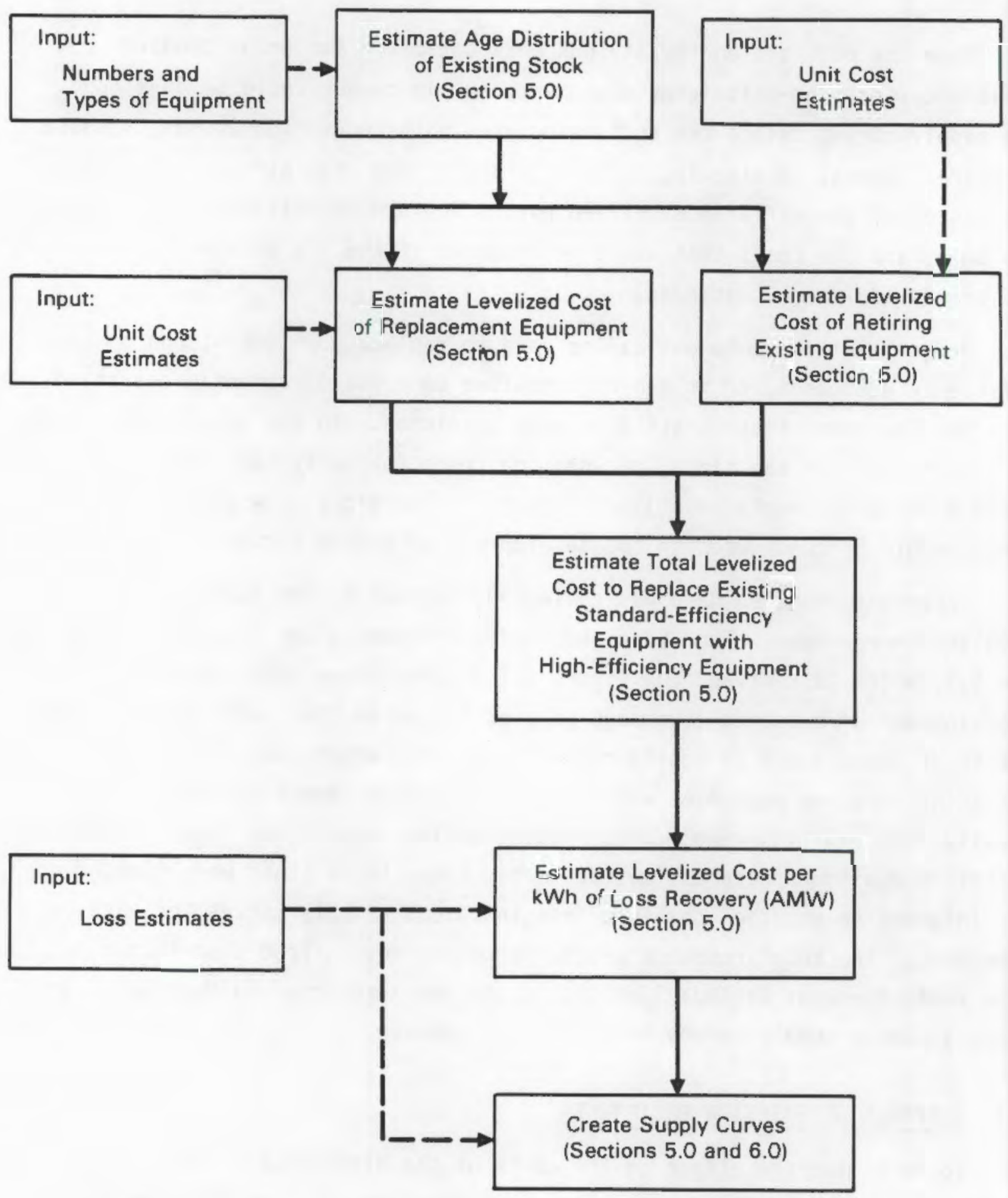

FIGURE 5.1. Input Steps for Development of the Supply Curves 
For example, if equipment has a thirty-year rated life and is twenty-years old, then the costs for normal replacement would normally be incurred 10 years from the present. However, if the equipment is replaced immediately with more efficient equipment, the costs would be incurred in the present year.

The number of the different types of equipment and their ages were calculated. Since the actual age distribution of the known current stock of equipment in the BPA region is unknown, the distribution of those ages was estimated. It was assumed that purchases of equipment needed to satisfy load growth was proportional to the growth rate of total electricity demand experienced by the region. For example, if the demand for electricity grew at an average compound rate of $2 \%$ over the past 10 years then it was assumed that the stock of transformers increased by that same rate.

However, satisfaction of load growth is not the only reason equipment is purchased. Replacements are also purchased for equipment that is retired during a given year. In this study, the amount of equipment that was retired in a year was assumed to be equal to the amount of equipment that reached its rated lifetime in that particular year. Therefore, the amount of equipment retired in any given year was dependent on the amount of equipment purchased " $X$ " years ago, where " $x$ " is the rated lifetime of the equipment.

The total amount of equipment that was purchased in any past year, then, was the sum of the amount of equipment purchased for replacement and the amount purchased to cover growth in the demand for electricity in that particular year. This sum was calculated in retrospect from the year of the analysis back to the rated lifetime of the equipment. A logical constraint that was applied was to require that equipment purchased in all of those years must equal the amount of existing equipment. The sum of equipment purchases and replacements in each year produced the age distribution for existing equipment. Figure 5.2 illustrates the resulting age distribution curve for distribution transformers.

\subsection{PAYMENT STREAM FOR REPLACING EQUIPMENT}

Once the age distribution of the equipment was estimated, the cost associated with replacing equipment of a given vintage could be calculated. For 


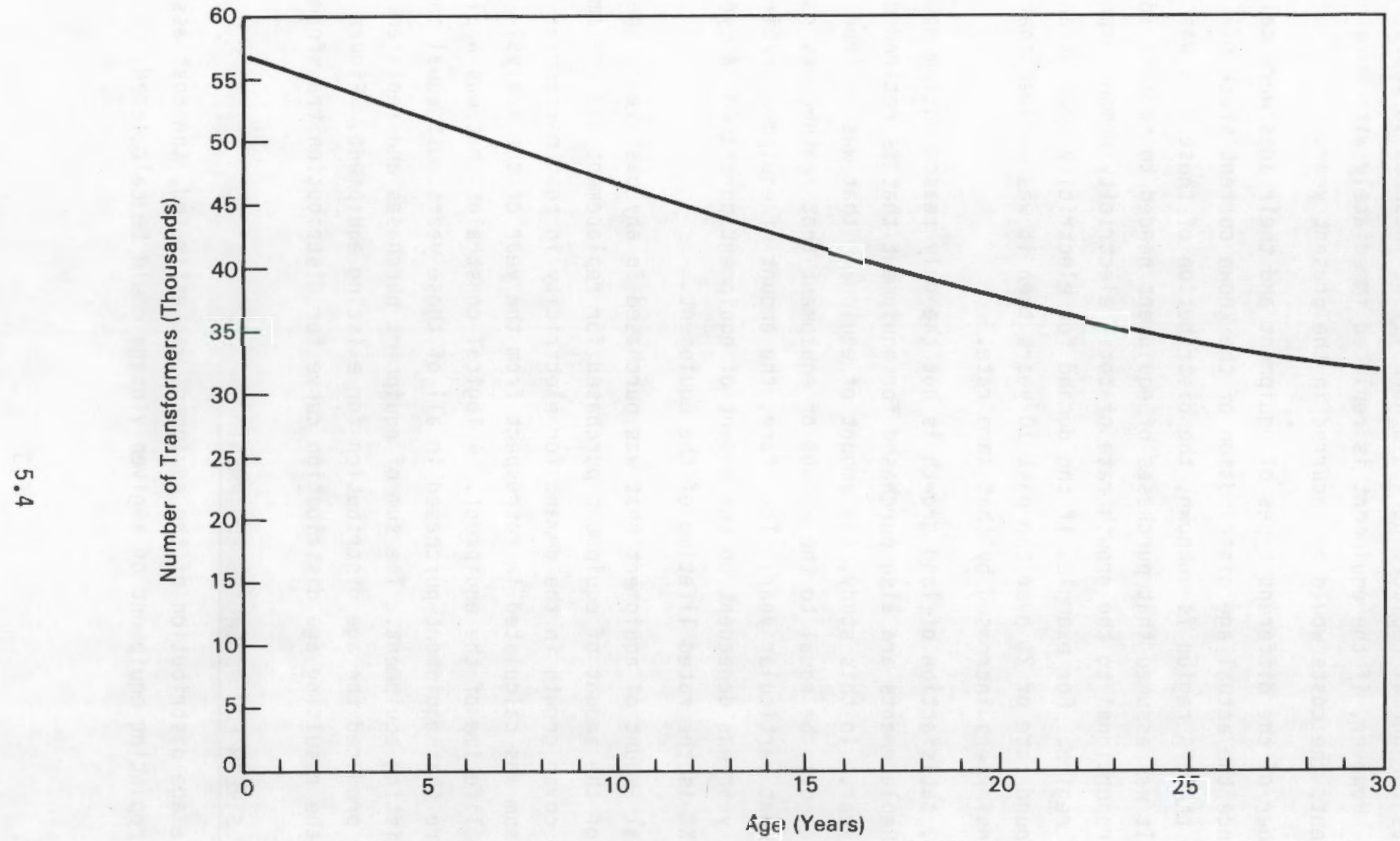

FIGURE 5.2. Age Distribution of Distribution Transformers 
each vintage and each equipment category, the cost streams produced when the utilities continued to operate with standard-efficiency equipment were calculated.

\subsubsection{Standard-Efficiency Equipment Costs}

Standard-efficiency equipment was assumed to be replaced only at the end of its rated life. It was also assumed that the equipment was financed using a fixed-payment, mortgage-type financial instrument. This assumption allowed the time value of money to be considered, since the interest paid on the instrument equalizes the value of money across time. The cost stream per year, then, was simply the fixed (equalized) payment on this instrument. When the rated lifetime of the equipment was reached, standard-efficiency replacement equipment was purchased using the same type of mortgage instrument.

The fixed payment was calculated by use of the following formula:

$$
\text { Fixed Payment }=(\text { Principal })\left(\frac{I(1+I)^{N}}{(1+I)^{N}-1}\right)
$$

where $I=$ real interest rate ( $3 \%$ was used in this analysis)

$N=$ number of payment years.

\subsubsection{High-Efficiency Equipment Costs}

The same calculation was used for high-efficiency equipment. Replacement of standard-efficiency equipment with high-efficiency equipment in the current year was made for each equipment vintage and equipment category. Highefficiency equipment purchases were also financed using a fixed-payment, mortgage-type financial instrument. However, where there was a remaining balance in the expected lifetime of standard-efficiency equipment being replaced, the remaining fixed payments were taken into account. The fixed payment for a particular type of standard-efficiency equipment of category $j, S_{j}$, is:

$$
\operatorname{SEP}_{j}=(\text { Cost of Standard Equipment in Category } j)\left(\frac{I(1+I)^{N}}{(1+I)^{N}-1}\right)
$$


The terms of this equation are the same as the previous equation.

The payment in year $k, E_{j k}$, for replacing standard-efficiency equipment with one year of life remaining is:

$$
\begin{aligned}
\text { EEP }_{j k 1}= & \{(\text { Cost of high-efficiency equipment in Category } j) x \\
& \left.\left(\frac{I(1+I)^{N}}{(1+I)^{N}-1}\right)\right\}+\left\{\begin{array}{l}
\text { SEP }_{j} \text { if } k<1_{1} \\
0 \text { otherwise }
\end{array}\right.
\end{aligned}
$$

Therefore, the total fixed payment incurred after the replacement was the sum of the fixed payment for the standard-efficiency equipment, until the remaining lifetime is reached, and the fixed payment for the new highefficiency equipment. In this study, a salvage value of zero was assumed for the standard-efficiency equipment that was replaced. If a different salvage value was assumed, the fixed payment for the standard-efficiency equipment could have been reduced by the amount of the salvage value.

The difference between the two total fixed payments in each year is the added cost of installing more efficient equipment for each year. The difference is equal to the fixed payment for the high-efficiency equipment alone until the lifetime of the original standard-efficiency equipment is reached. Beyond this time, the increment is the difference between the fixed payment for the high-efficiency equipment and the standard-efficiency equipment. For any particular type of equipment, $j$, and vintage, 1 , the total added payment for year, $k$, for the replacement program, $D I_{j k 1}$, is the difference between the two payments multiplied by the amount of equipment:

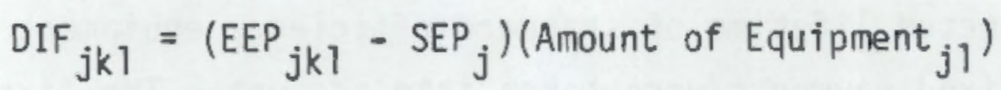

Because of variations introduced by the remaining lifetime of each vintage, the resulting total cost streams vary from year to year. To convert this 
variable cost stream to a constant cost per year, the cost streams were levelized by first calculating the present value of the cost streams, PVDIF ${ }_{j 1}$ :

$$
\operatorname{PVDIF}_{j 1}=\sum_{k=1}^{N} D F_{j k 1} \div(1+I)^{k}
$$

The present value was then distributed to each year according to a fixedpayment mortgage schedule whose term was the life expectancy of the component:

$$
\text { Replacement Fixed Payment }_{j 1}=\left(\text { PVDIF }_{j 1}\right)\left(\frac{I(1+I)^{N}}{(1+I)^{N}-1}\right)
$$

The resultant values were the fixed amount incurred per year to replace standard-efficiency equipment of a certain category and a certain vintage with more efficient equipment.

\subsection{AVERAGE POWER AND ENERGY SAVINGS}

To form the supply functions, the cost information developed using the methods described above was then combined with the power savings that result from use of more efficient equipment. Losses were first estimated for both standard-efficiency equipment and high-efficiency equipment for each category, as described in Section 4.0. The loss savings were calculated in terms of average watts per unit of equipment. Multiplying the loss figure by the number of units of equipment in each equipment category and each vintage, and then dividing by 1 million yielded average megawatt (AMW) loss recovery for each category and vintage of equipment:

$$
A M W_{j 1}=\frac{\left(\text { Loss }_{j 1} \times \text { Amount of Equipment }_{j 1}\right)}{10^{6}}
$$


Multiplying the loss recovery by 8760 (the number of hours in a year) produced the AMW-hour (AMWh) energy savings for each category and vintage in a particular year.

The additional (levelized) cost per year of replacement with more efficient equipment was then divided by the average kilowatt-hour savings per year (AMWh savings times 1000). The result was the cost per kilowatt-hour of electricity saved by replacing standard-efficiency equipment with high-efficiency equipment.

$$
\text { Cost per Kilowatt Hour }{ }_{j 1}=\frac{\text { Replacement Fixed Payment }_{j 1}}{\left(\mathrm{AMW}_{\mathrm{j} 1} \times 8,760 \times 1000\right)}
$$

Finally, the cost per kilowatt hour was expressed as a function of the AMW savings to produce supply curves for each of the conservation resources considered. 


\subsection{RESULTS UF SUPPLY CURVE ESTIMATION}

Using the methodologies described in previous sections, supply curves were developed to determine the conservation potential of efficiency improvements that are technically and economically feasible when applied to the T\&D systems of utilities in the BPA service area. The measures considered were replacement. of distribution and substation transformers with more efficient units, reconductoring transmission lines and primary distribution feeders, and upgrading the voltage of the $12.5 \mathrm{kV}$ distribution system to $34.5 \mathrm{kV}$. The major portion of the potential for efficiency improvement in Pacific Northwest T\&D systems can be associated with these components. The loss reduction potential of these measures is discussed at two levels of cost: 2 and 5.5 cents/kWh in 1980 dollars. Table 6.1 summarizes the results of regional supply curve analyses.

The equipment replacement measures provide a total loss recovery of approximately $233 \mathrm{AMW}$ at 5.5 cents $/ \mathrm{kWh}$. The supply curve for the voltage upgrade option was generated to evaluate an alternative to equipment replacement and to provide a first order comparison between two principal conservation

TABLE 6.1. Loss Recovery Potential and Cost (1980\$) of Pacific Northwest Regional T\&D System Efficiency Improvements

Loss Reduction Measure

Transformer/Line Replacement

Replace Distribution Transformers

Replace Substation Transformers

Reconduct or Primary Feeders

Reconductor Transmission Lines

Total of Above Transformer and Line

Replacement Measures

Voltage Upgrade

Combination of Voltage Upgrade and Balance of Equipment Replacement
Loss Recovery (AMW)

Cost (cents $/ \mathrm{kWh}$ ) 
approaches. Upgrading $12.5 \mathrm{kV}$ distribution systems in the Pacific Northwest to $34.5 \mathrm{kV}$ was estimated to recover a 276 AMW resource at just less than 2 cents/kWh. Since these systems represent approximately $75 \%$ of customer utilities' circuit miles, credit can be taken for applying the above equipment replacement measures to the balance of the system not affected by the voltage upgrade. The combination of 1) upgrading voltage, 2) replacing the remaining $25 \%$ of the region's distribution transformers, 3) reconductoring approximately $25 \%$ of the primary feeders, 4) replacing substation transformers, and 5) reconductoring customer-owned transmission lines results in an estimated total conservation resource of $380 \mathrm{AMW}$ at $5.5 \mathrm{cents} / \mathrm{kWh}$. Due to the dominance of the lower cost of the voltage upgrade, over $77 \%$ of this resource (293 AMW) is potentially available at a cost of 2 cents $/ \mathrm{kWh}$.

Characteristics of each supply curve are discussed below.

\subsection{DISTRIBUTION TRANSFORMER REPLACEMENT}

The supply curve for distribution transformers (see Figure 6.1) is a relatively smooth curve that starts at 1.2 cents/kWh and 2 AMW and rises to 5.5 cents $/ \mathrm{kWh}$ at $78 \mathrm{AMW}$. The lower figure represents replacement of transformers near the end of their rated life, which is assumed to be 30 years. The higher figure is for replacement of transformers that were purchased and installed the previous year.

A slight concavity of the supply curve with respect to the horizontal axis is evident at very low values of cost. The curve then becomes convex at higher levels of cost. The changes in shape are due to two interacting factors: transformer vintage and transformer size. For a particular vintage of transformer (e.g., all sizes that are 25 years old), the supply curve is convex to the horizontal axis. However, analysis of various vintages of a specific size transformer results in a supply curve that is slightly concave to the horizontal axis. Only one size of transformer generates savings at low levels of cost (from 1.2 cents/kWh to approximately 3.5 cents/kWh), so only the effect of transformer vintage is displayed in that region. At other levels of cost, the changing size of transformers becomes important and leads to a more convex curve. The tendency for the supply curve to saturate the resource is not as 
a

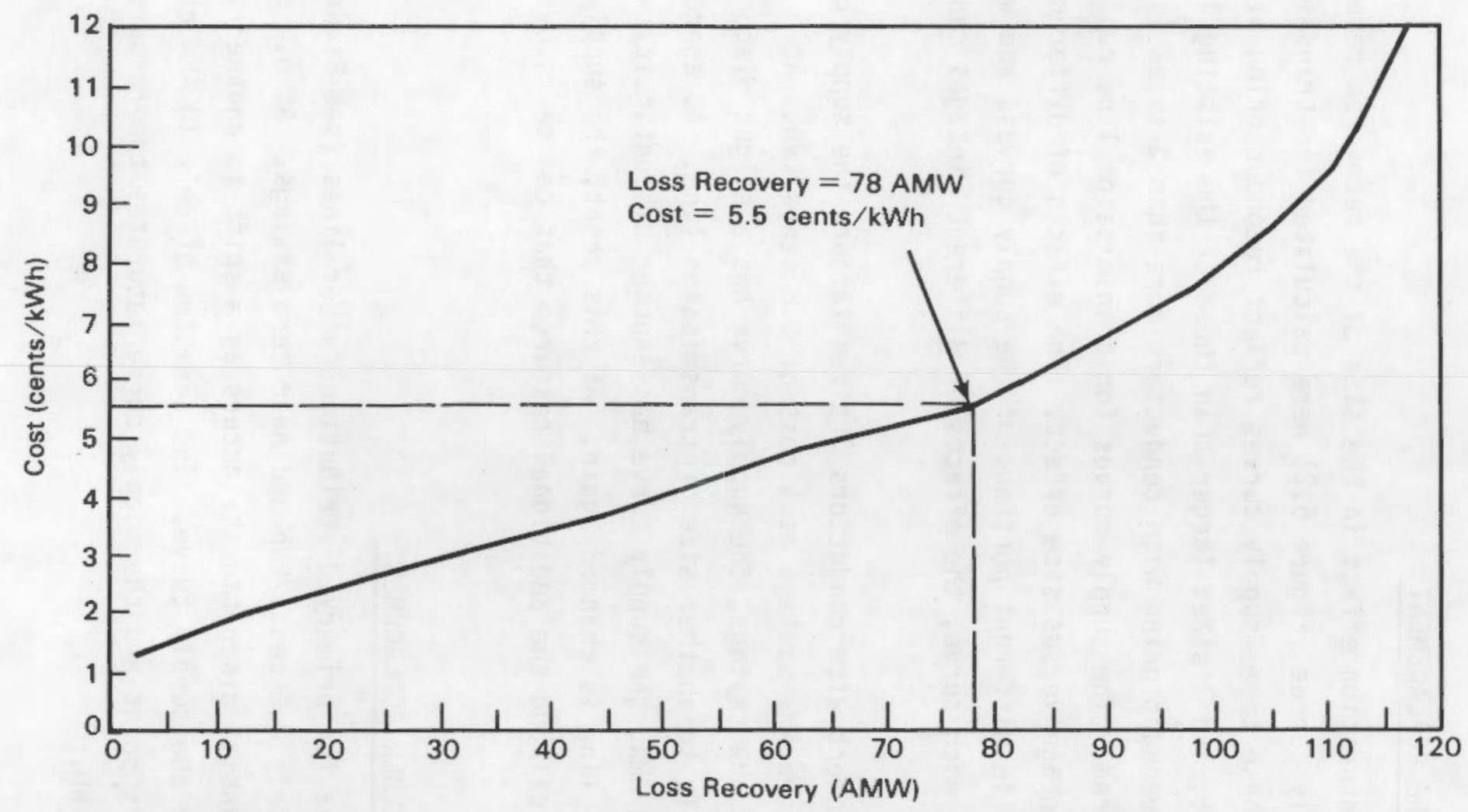

FIGURE 6.1. Supply Curve for Replacement of Standard-Efficiency Distribution Transformers with High-Efficiency Units 
abrupt as with the other measures considered and an additional resource of approximately $40 \mathrm{AMW}$ is available at costs of up to 12 cents $/ \mathrm{kWh}$.

\subsection{TRANSMISSION LINE REPLACEMENT}

To test for a saturation effect in the size of the recovered resource, three different supply curves (Figure 6.2) were calculated for transmission line replacement. These three supply curves reflect reconductoring with conductors that are 3, 5, and 7 sizes larger than those of the existing lines. In standard practice, reconductoring with conductors more than 3 sizes larger would not be considered. The supply curves for transmission line replacement show a pronounced vintage versus size effect. The effects of different sizes of lines can be seen in different portions of the supply curves, and within a particular region of each curve, the effects of different vintages can also be seen.

For line replacement with conductors 3 sizes larger, the supply curve starts at close to zero AMW savings at a cost of 0.8 cents $/ \mathrm{kWh}$. At 4.2 cents/kWh and $30 \mathrm{AMW}$ savings, the supply curve has a slight discontinuity that indicates a shift to another size of transmission line. At approximately 5.5 cents/kWh and $48 \mathrm{AMW}$, the supply curve has another discontinuity where the size of transmission line is changed again. At this point, the supply curve becomes almost vertical and the additional resource that can be recovered becomes very small.

\subsection{DISTRIBUTION FEEDER REPLACEMENT}

The supply curve for primary distribution feeder lines (see Figure 6.3) starts at approximately 0.8 cents $/ \mathrm{kWh}$ and near zero savings. At 5.5 cents $/ \mathrm{kWh}$ and $98 \mathrm{AMW}$, a substantial discontinuity occurs as a shift to another size of line is reflected in the supply curve. The addition of only 10 AMW can be recovered beyond this point and the supply curve saturates the resource at a cost of 11.6 cents/kWh. 


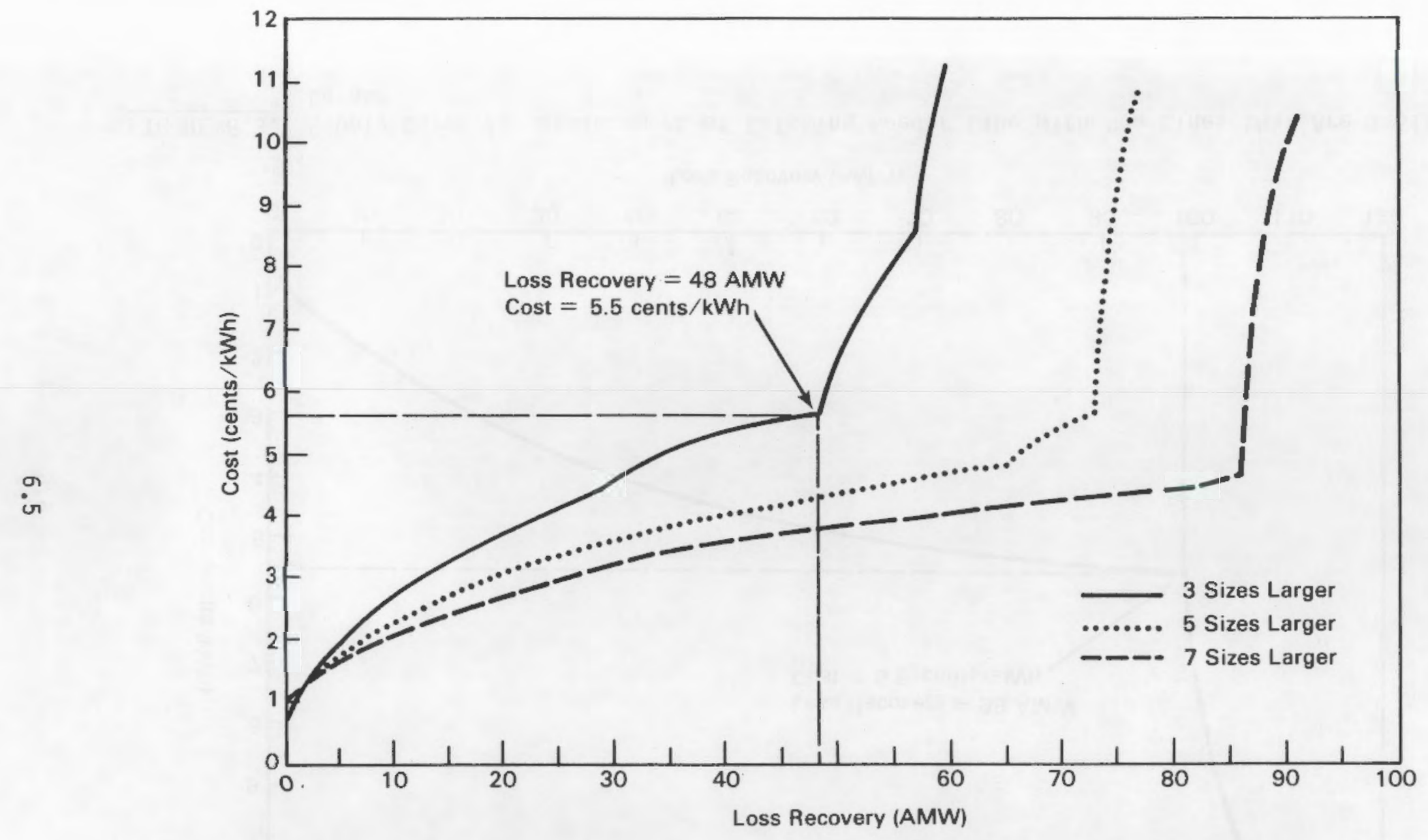

FIGURE 6.2. Supply Curves for Replacement of Existing Transmission Lines with New Lines that Are 3, 5, and 7 Sizes Larger 


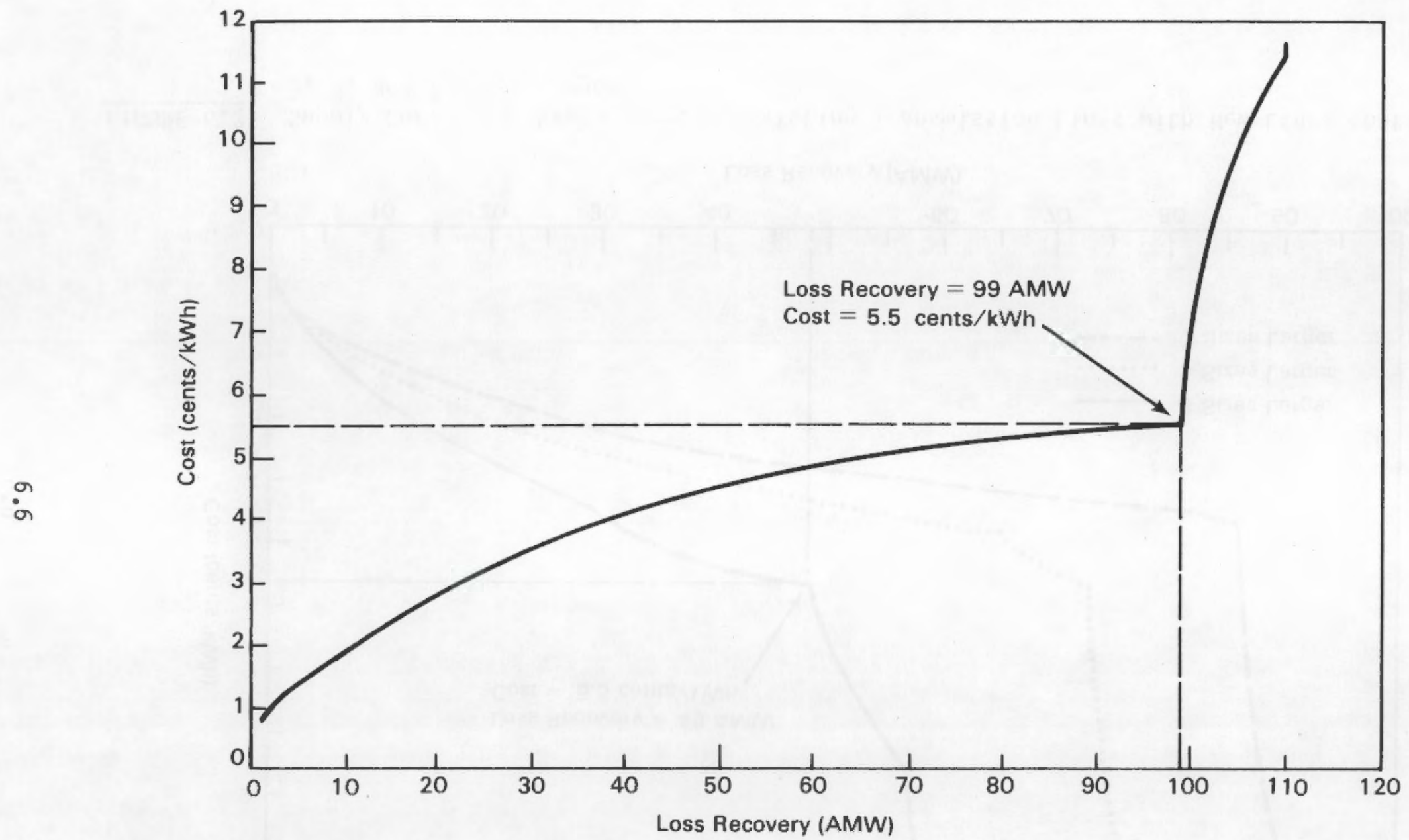

FIGURE 6.3. Supply Curve for Replacement of Existing Feeder Line with New Lines that Are 3 Sizes Larger 


\subsection{SUBSTATION TRANSFORMER REPLACEMENT}

Existing substation transformers are generally very efficient. Furthermore, based on the average peak load being carried, the equipment currently installed throughout the Pacific Northwest appears to be somewhat oversized. Therefore, estimated losses were found to be typically very small in relation to the transformer ratings. The cost of replacing these expensive transformers with more efficient equipment is substantial and is probably not worthwhile given their size and the small improvements in efficiency that are possible.

The estimated supply curve (Figure 6.4 ) shows very little savings at any

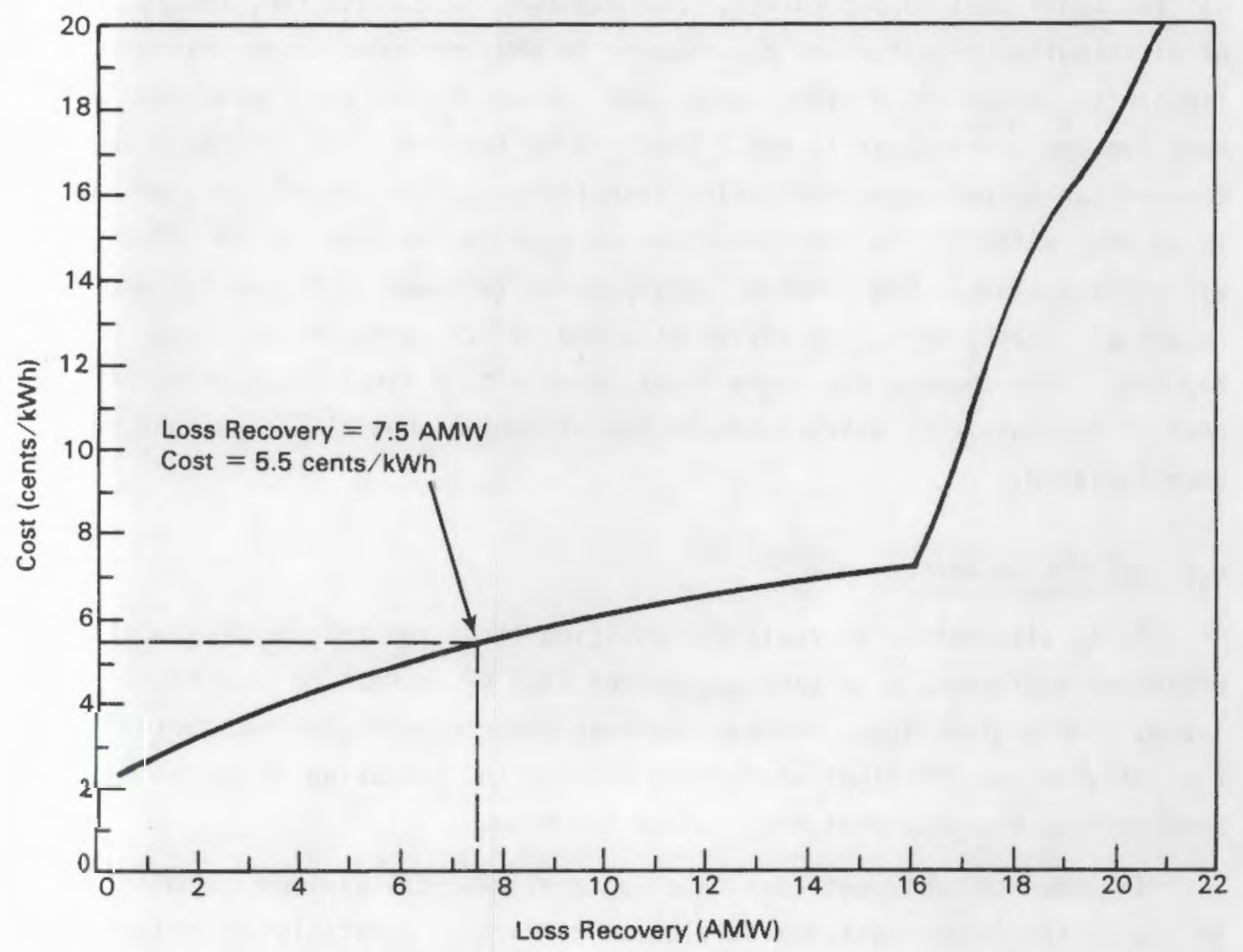

FIGURE 6.4. Supply Curve for Replacement of Standard-Efficiency Substation Transformers with High-Efficiency Units 
reasonable level of cost. The supply curve starts at 2.4 cents $/ \mathrm{kWh}$ and $0.5 \mathrm{AMW}$. A substantial discontinuity occurs in the curve at 7.2 cents $/ \mathrm{kWh}$ and 16 AMW where a shift to another size transformer is reflected. Finally, at 20 cents/kWh and $21 \mathrm{AMW}$, the amount of loss that can be recovered from substation transformers is exhausted. Only 7.5 AMW can be recovered at a cost of 5.5 cents $/ \mathrm{kWh}$.

\subsection{COMBINED TRANSFORMER AND LINE REPLACEMENT}

A supply curve that combines the loss recovery potential of all of the previously considered measures can be obtained by taking the horizontal sum of all the individual supply curves. For example, at 2 cents $/ \mathrm{kWh}$, the replacement of distribution transformers can recover 14 AMW, reconductoring transmission lines with conductors 3 sizes larger can recover $5 \mathrm{AMW}$, and reconductoring primary feeders can recover $11 \mathrm{AMW}$. There is no loss recovery available at 2 cents/kWh by replacing substation transformers. The sum of these resources is $30 \mathrm{AMW}$, which is the loss reduction at 2 cents $/ \mathrm{kWh}$ that can be effected by all these options. The combined supply curve is shown in Figure 6.5 and is relatively flat from 0.4 cents $/ \mathrm{kWh}$ at 2 AMW to 5.5 cents $/ \mathrm{kWh}$ at about

233 AMW. From then on the curve rises sharply to a final value of 284 AMW at a cost of 20 cents/kWh, which reflects the situation when all components have been replaced.

\subsection{VOLTAGE UPGRADE}

As an alternative to replacing existing lines and transformers with more efficient equipment, a voltage upgrade of $12.5 \mathrm{kV}$ feeders to $34.5 \mathrm{kV}$ was analyzed. For a given load, voltage upgrades can reduce losses substantially in transinission and distribution systems because the reduction in losses is proportional to the square of the voltage increase.

In order to implement a voltage upgrade, however, various components connected to the feeder system must also be upgraded. Substation transformers must be changed to provide the higher voltage, and insulators on the feeder 


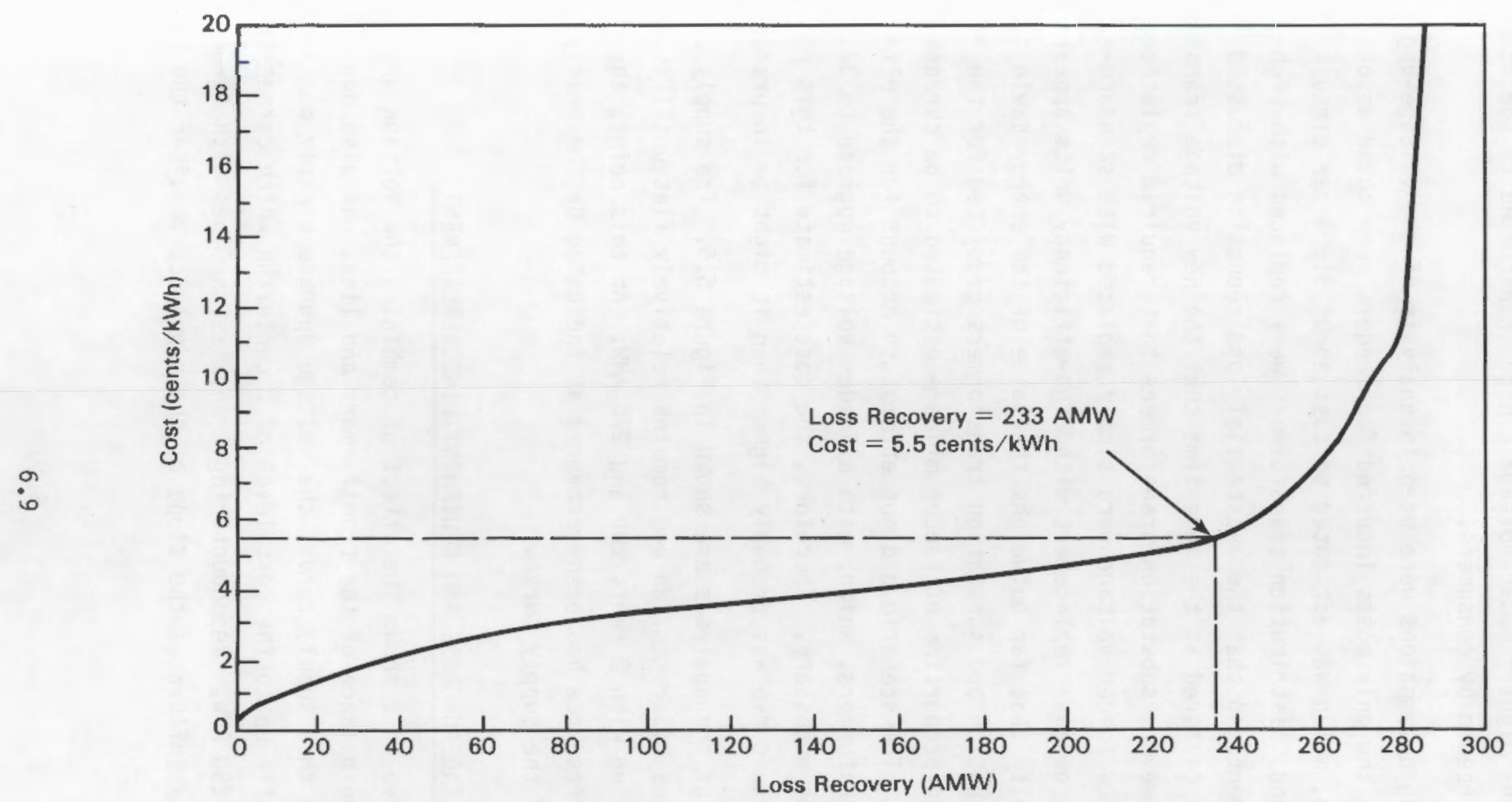

FIGURE 6.5. Supply Curve for Combined Transformer and Line Replacement 
lines also must be replaced. Finally, distribution transformers must be changed so that the higher feeder voltage can be transformed to the standard service voltages needed by consumers.

The following assumptions were used in analysis of the voltage-upgrade scenario. First, the only costs incurred for feeders were those associated with reinsulation, which was estimated to cost about $\$ 1500$ per circuit-mile (BPA 1981). Second, distribution transformers were replaced with highefficiency equipment, so that the substantial loss reduction discussed in Section 6.1 could be captured at the same time that the new voltage transformation was achieved. However, substation transformers that required replacement to accommodate the new feeder voltage were simply replaced with standard-efficiency equipment, because replacement with high-efficiency units appears to carry a cost penalty that far outweighs the value of the energy savings. The numbers of distribution and substation transformers predicted for the region were scaled to the proportion of feeder mileage estimated to be currently operating at $12.5 \mathrm{kV}$. The scenario did not attempt to account for the elimination of substation transformers, which, with a feeder voltage upgrade to $34.5 \mathrm{kV}$, would no longer be necessary. Therefore, the cost estimate for this portion of the voltage upgrade curve was probably higher than it might be in practice.

The results of the analysis are shown in Figure 6.6. The supply curve starts at 4 AMW and 0.3 cents/kWh and remains relatively flat until it reaches the point coinciding with 2 cents/kWh and 276 AMW. At this point, the majority of the potential resource has been recovered as indicated by the nearlyvertical trend of the supply curve.

\subsection{COMBINED VOLTAGE UPGRADE AND EQUIPMENT/LINE REPLACEMENT}

A supply curve that shows the effect of combining the voltage upgrade with replacement of the balance of the transformers and lines was also developed (Figure 6.7). In this supply curve, the voltage upgrade clearly dominates loss recovery, especially up to the cost level of 2 cents/kWh which corresponds to a loss recovery of 293 AMW. Reconductoring transmission lines with larger sized conductors heavily influences the slope of the supply curve after the 293 AMW 


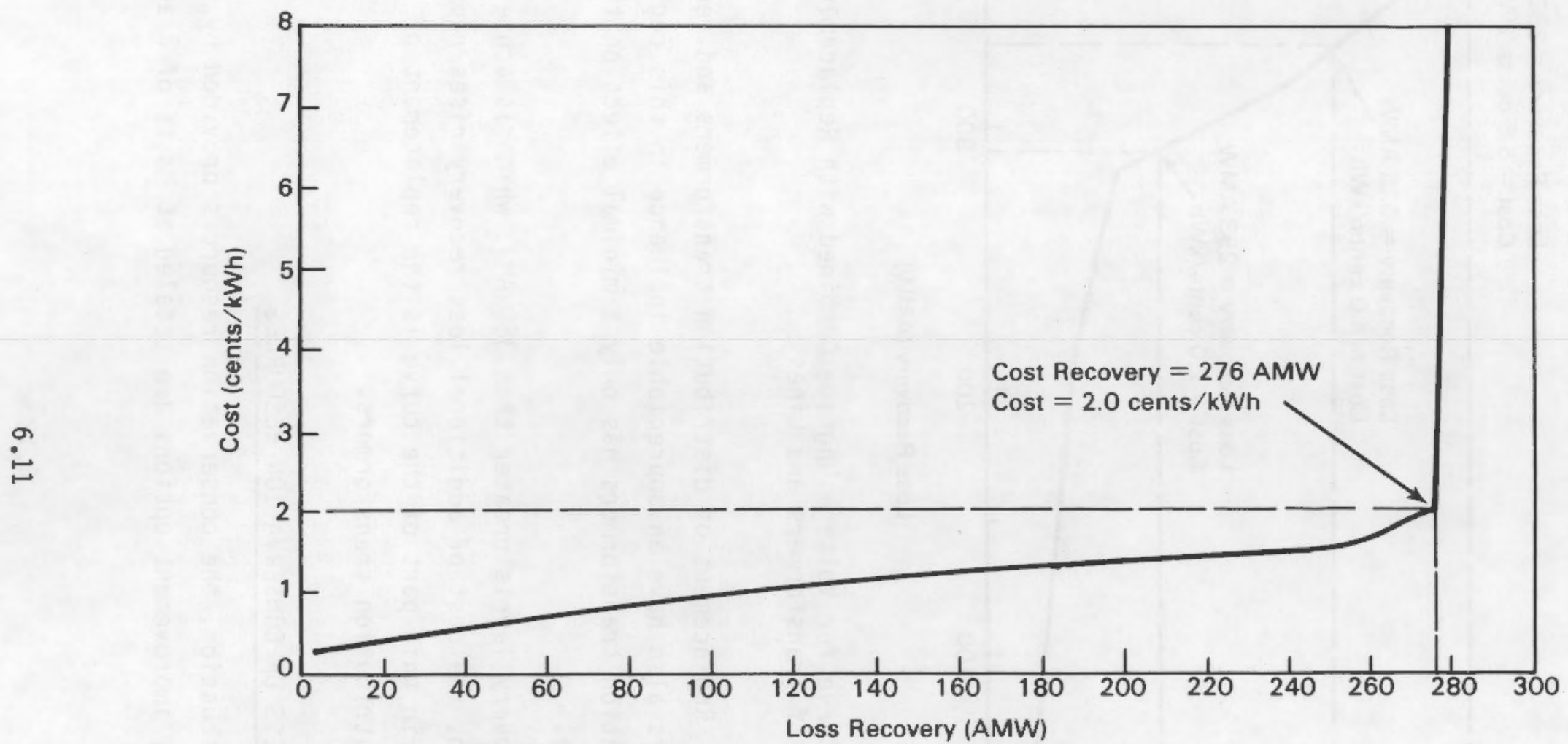

FIGURE 6.6. Supply Curve for Voltage Upgrade of the Existing $12.5 \mathrm{kV}$ System to $34 \mathrm{kV}$ 


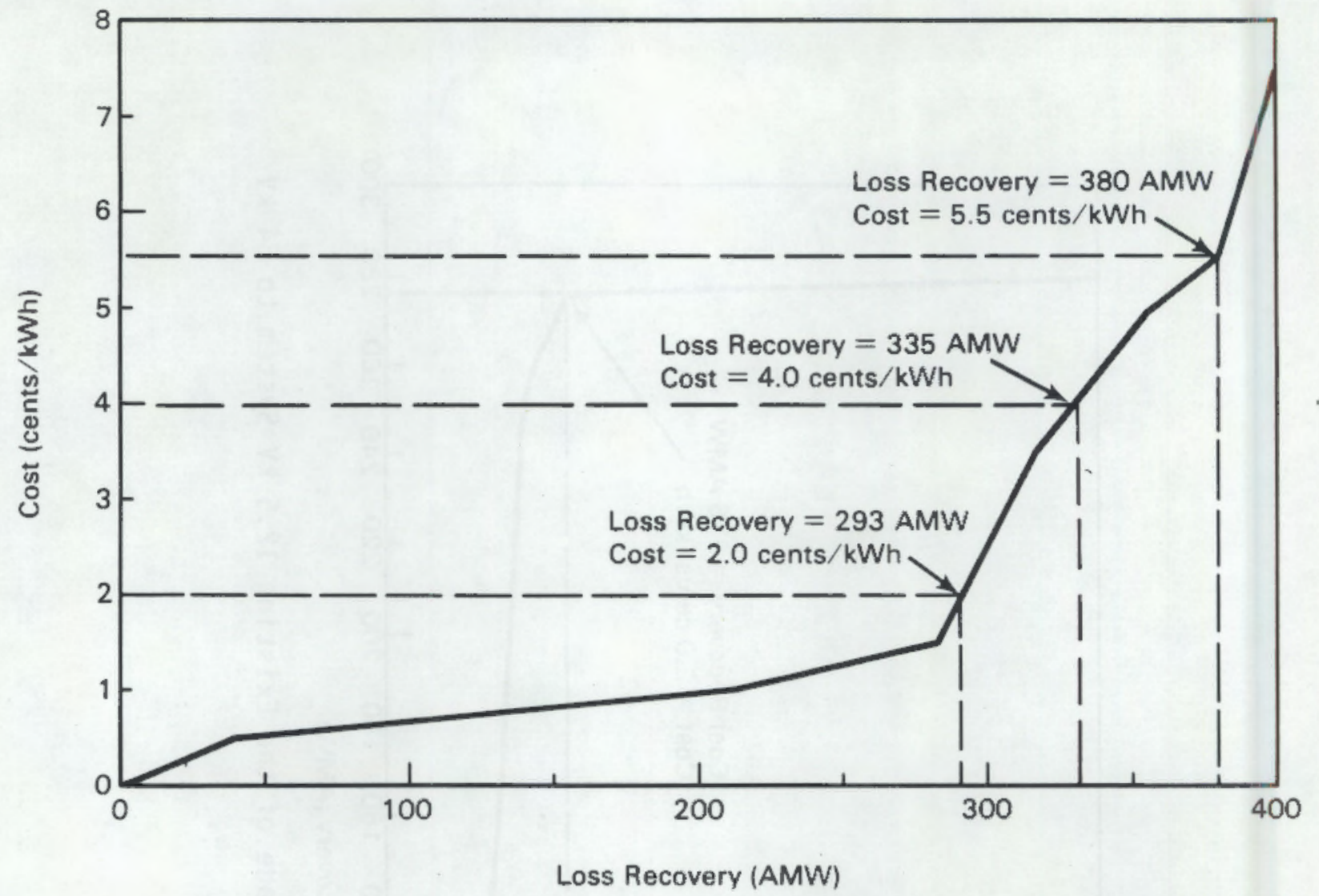

FIGURE 6.7. Supply Curve for Voltage Upgrade Combined with Replacement of the Balance of Transformers and Lines

loss-recovery level. Replacement of distribution transformers and reconductoring primary feeders also have an appreciable influence in this region. Replacement of substation transformers has only a minimal effect on the curvature of this schedule.

At all loss-recovery levels greater than $380 \mathrm{AMW}$, which is achieved at a cost of 5.5 cents $/ \mathrm{kWh}$, the cost of additional loss recovery rises rapidly. The most dominant factor in this part of the curve is the replacement of the transmission lines and distribution transformers.

6.8 COST-EFFECTIVENESS OF CONSERVATION RESOURCES

In the above discussion, the conservation resources provided by the major $T \& D$ system efficiency improvement options are totaled at costs of 2 and 
5.5 cents $/$ kWh. These costs were chosen to account for the significant saturation tendencies of the voltage upgrade and equipment replacement options, respectively.

The NWPPC has established that T\&D system conservation may be a costeffective alternative to capacity addition up to a cost of approximately 5 cents/kWh in 1985 dollars (NWPPC 1986). This level of cost is equivalent to approximately 4 cents/kWh in 1980 dollars if allowance is made for $22 \%$ inflation in T\&D system costs between 1980 and 1985, as indicated by the HandyWhitman Index. Figure 6.7 shows a loss reduction potential of 335 AMW at 4 cents/kWh in 1980 dollars. This resource represents, therefore, the T\&D system efficiency improvement potential available in the Pacific Northwest at 5 cents/kWh in 1985 dollars.

\subsection{PUBLICLY-OWNED UTILITY T\&D SYSTEM EFFICIENCY IMPROVEMENTS}

The supply curves presented above represent the major conservation components available from improving the T\&D efficiency of both POUs and investorowned utilities (IOUs) in the BPA service area. The conservation resources of most interest to BPA are those that may be acquired on POU systems, principally comprised of public utility districts, rural electric cooperatives and municipally-owned utility systems. These are the so-called "preference customers" that have the legal right of priority access to federally-generated power in the Pacific Northwest.

System characterization data for the Pacific Northwest region were disaggregated to estimate the T\&D component stocks that can be associated with the POUs in the region. On the basis of this disaggregation, the loss reduction potential and corresponding costs of efficiency improvements applied only to the POU portion of the Pacific Northwest T\&D system were estimated using the methodologies described previously. The results of this additional analysis are summarized in Table 6.2 with loss recovery and costs expressed, as before, in average megawatts and 1980 dollars, respectively. The resource resulting from the combination of voltage upgrades and equipment replacement was estimated in the same manner as described for the corresponding item in Table 6.1. 
TABLE 6.2. Loss Recovery Potential and Cost (1980\$) of POU T\&D System Efficiency Improvements

\begin{tabular}{|c|c|c|}
\hline Loss Reduction Measure & $\begin{array}{l}\text { Loss Recovery } \\
\text { (AMW) }\end{array}$ & $\begin{array}{c}\text { Cost } \\
\text { (cents } / \mathrm{kWh} \text { ) } \\
\end{array}$ \\
\hline \multicolumn{3}{|l|}{ Transformer/Line Replacement } \\
\hline Replace Distribution Transformers & 29 & 5.5 \\
\hline Replace Substation Transformers & 3 & 5.5 \\
\hline Reconductor Primary Feeders & 52 & 5.5 \\
\hline Reconductor Transmission Lines & 7 & 5.5 \\
\hline $\begin{array}{l}\text { Total of Above Transformer and Line } \\
\text { Replacement Measures }\end{array}$ & 91 & 5.5 \\
\hline Voltage Upgrade & 120 & 2.0 \\
\hline $\begin{array}{l}\text { Combination of Voltage Upgrade and } \\
\text { Balance of Equipment Replacement }\end{array}$ & 150 & 5.5 \\
\hline
\end{tabular}

Table 6.3 compares resource components from Tables 6.1 and 6.2 to show the percentage of the regional resource created by each conservation measure that is potentially available on Pacific Northwest POU systems. With the exception of primary feeder and transmission line reconductoring, the magnitude of POU resources are approximately $40 \%$ of the corresponding regional resources. The 53\% contribution from POU primary feeders is balanced by the 15\% 1oss recovery potential on POU transmission lines. This can be correlated to the POUs having proportionally more of their systems involved in power distribution and the IOUs maintaining larger transmission systems.

As a result of using common methodologies, the shapes of POU supply curves were found to duplicate those of the corresponding curves for the region (Figures 6.1 through 6.7 ). The principal difference between the POU curves and the regional curves was the reduced resource size associated with the POU portion of the T\&D system at each level of cost. Figure 6.8 shows the supply curve for POUs that combines the voltage upgrade resource with loss recovery provided by the replacement of the remaining transformers and lines. Similarly, as in Figure 6.7 (combination supply curve for the region), the POU curve is 
TABLE 6.3. Percentage of Regional T\&D Conservation Resources Available on POU Systems in the BPA Service Area

\begin{tabular}{|c|c|c|c|}
\hline \multirow[b]{2}{*}{ Loss Reduction Measure } & \multicolumn{2}{|c|}{ Resource (AMW) } & \multirow{2}{*}{$\begin{array}{c}\text { POU } \\
\text { Percentage } \\
\end{array}$} \\
\hline & Region & JUs Only & \\
\hline \multicolumn{4}{|l|}{ Transformer/Line Replacement } \\
\hline Replace Distribution Transformers & 78 & 29 & 37 \\
\hline Replace Substation Transformers & 8 & 3 & 38 \\
\hline Reconductor Primary Feeders & 99 & 52 & 53 \\
\hline Reconductor Transmission Lines & 48 & 7 & 15 \\
\hline $\begin{array}{l}\text { Total of Above Transformer and Line } \\
\text { Replacement Measures }\end{array}$ & 233 & 91 & 39 \\
\hline Voltage Upgrade & 276 & 120 & 43 \\
\hline $\begin{array}{l}\text { Combination of Voltage Upgrade and } \\
\text { Balance of Equipment Replacement }\end{array}$ & 380 & 150 & 39 \\
\hline
\end{tabular}

dominated by the voltage upgrade resource up to costs of 2 cents/kWh. The balance of the curve is contributed by the relatively smaller loss reduction components resulting from the other measures. The combined PoU supply curve indicates resources of 125 and 150 AMW at 2 and 5.5 cents/kWh, respectively, in 1980 dollars. The 137 AMW resource available at the equivalent of 5 cents/kWh in 1985 dollars (4 cents/Kwh in 1980 dollars) represents the T\&D conservation potential achievable, according to the NWPPC cost-effectiveness criterion, on POU systems in the BPA service area.

\subsection{ACCURACY OF SUPPLY CURVE ESTIMATES}

The analyses for both the equipment replacement and the voltage upgrade options are highly dependent on the quality of the data used. Biases that may be present in the CSEI survey data could create biases in the supply curves. An important possible bias could exist if the utilities that responded to the survey were already engaged in planning and management efforts to maintain efficient systems. The responses they provided may be biased towards efficient systems and, therefore, may understate the conservation potential of a more 


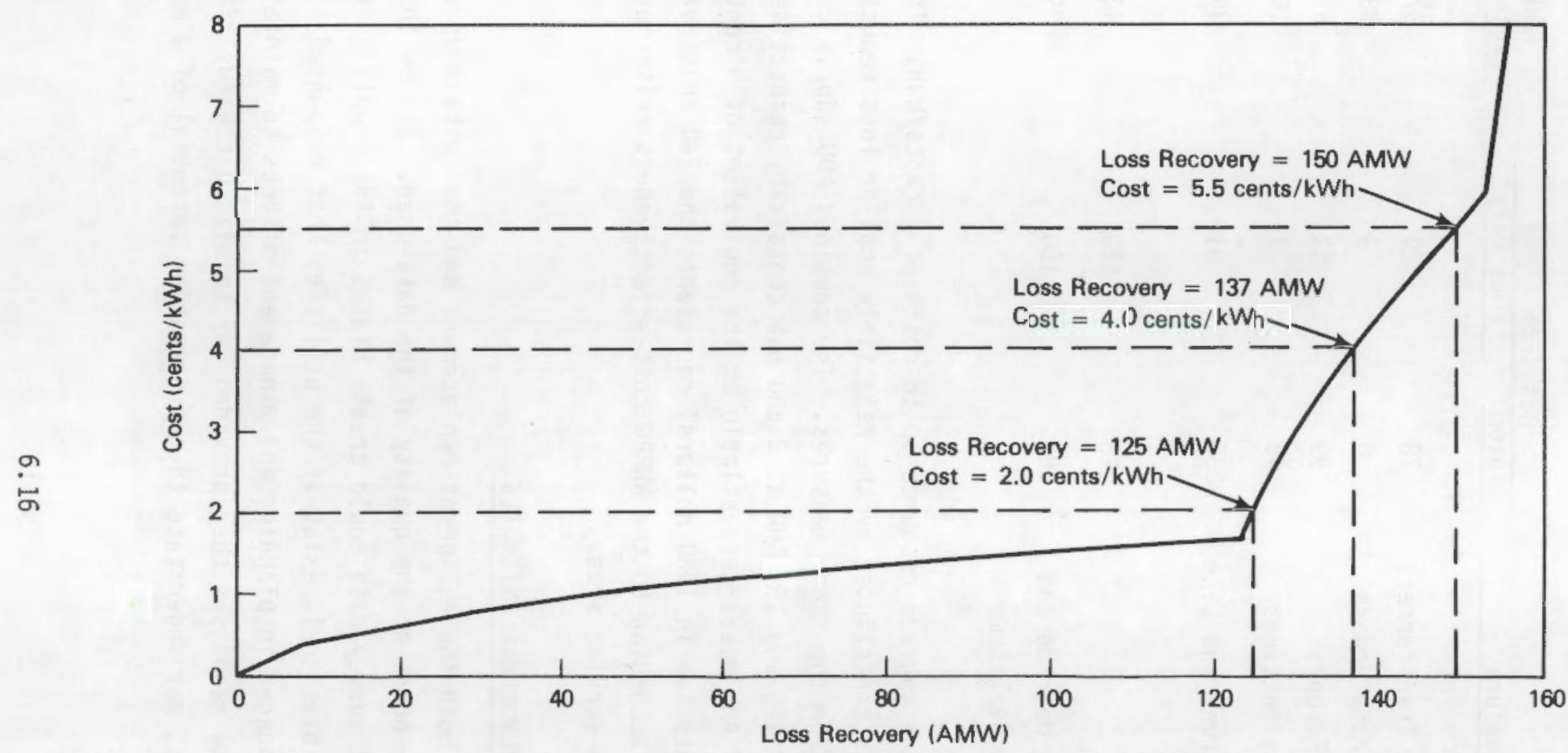

FIGURE 6.8. Supply Curve for Voltage Upgrade Combined with Replacement of the Balance of Transformers and Lines for POUs 
representative sample of all systems. Without additional information on nonrespondent utilities, this possibility could not be tested.

Great care was taken to use data in an appropriate manner during the development of information for use in the component characterization and the loss estimates that supported the supply function analysis. For example, prior to the use of the survey data for estimating component losses, the rows of data in the data base were systematically screened, corrected when possible, or eliminated from the analysis if elements essential in calculating losses were missing. Obviously inaccurate data were also eliminated from the files used for developing component average characteristics and loss levels.

Parameters that were obtained from literature sources rather than from the survey may not be appropriate for the distribution systems in the Pacific Northwest at the present time. Use of these parameters (primarily no-load and load-loss levels for distribution transformers, and the distribution factor used for feeder loss calculations) may have introduced some bias in the loss estimates. However, without more reliable, region-specific information for comparison, it is difficult to tell whether such a bias would produce higher or lower levels of loss. While slightly different results are possible, it is unlikely that transformer loss estimates would change significantly if regional specific no-load and load losses were known. Similarly, the use of a national average distribution factor in place of a regional figure is unlikely to affect feeder loss estimates in a substantial manner.

Another possible source of error, which could exist in the estimates of distribution transformer loss reduction potential, is the assumption that the existing transformer stock is made up of standard-efficiency (97.8\%) equipment. Use of more efficient transformers has become quite commonplace for many utilities. Since the region's distribution system experienced much of its growth in recent years, it is entirely possible that many of the new transformers added to accommodate growth were of higher than standard-efficiency. If this is so, then losses (and, therefore, savings from transformer replacement) may be somewhat overstated in this report.

The size of the regional stock, which was estimated by regression analysis, could also be in error due either to possible biases in the sample (due to 
self-selection on the part of respondents) or the lack of strong relationships between dependent and independent variables. Feeder circuit miles could be most influenced by these considerations because of the large variance in the statistical parameters.

It appears that there is a significant excess capacity in the T\&D systems of many BPA customers, especially in substation transformers. The excess capacity in T\&D equipment is consistent with the excess capacity existing elsewhere in Pacific Northwest power systems due, in large part, to the decrease in demand growth experienced by the region and the fact that many components purchased in the 1970's were deliberately oversized. Because losses are reduced when equipment operates at less than rated loads, replacement of such equipment with more efficient components would result in more modest loss reductions. In these cases, the cost of equipment replacement is less justifiable than in cases where existing equipment is operating at levels near its rated capacity. Because most of the transformers in the sample were under-loaded, the analysis may overstate the recoverable resource.

The assumption of a high efficiency factor (1.42) in the cost estimate for substation transformers may have the effect of shifting the supply curve to high costs throughout its range. The supply curve is fairly flat in the range between 8 to $16 \mathrm{AMN}$. A sinall reduction in cost could bring more of this curve below the cost-effectiveness threshold.

In the voitage upgrade scenario, no credit was taken for improving substation transformer efficiency or for eliminating some of the stock entirely. These would have the effect of slightly increasing the resource and reducing costs, respectively.

All of the above potential sources of error are considered to be small in relation to the system characteristics and data inputs that dominate the supply analysis. The combined effect of these relatively small biases and errors are expected to generaliy cancel each other or, at the most, produce a conservative aggregate tendency in the supply curve estimates. 


\subsection{CONCLUSIONS}

Supply curves were estimated for the major efficiency improvement (10ssreduction) options that have potential application on the T\&D systems of POUS and IOUs in the BPA service area. The conservation resources provided by these options were totaled at two levels of cost (2 and 5.5 cents/kwh in 1980 dollars) to reflect the principal steps in the combined supply curve of all options considered.

The voltage upgrade option that consists of increasing the voltage of $12.5 \mathrm{kV}$ feeders to $34.5 \mathrm{kV}$ was estimated to provide a recoverable resource of $276 \mathrm{AMW}$ at a cost of 2.0 cents/kWh. The significantly higher energy savings and lower cost of this option when compared to any equipment replacement program is a significant result. In comparison to the component replacement approach, a region-wide voltage increase of the $12.5 \mathrm{kV}$ system to $34.5 \mathrm{kV}$ clearly appears to be the superior loss reduction option.

At a cost of 5.5 cents $/ k$ Wh recovered, a program that replaces distribution transformers and substation transformers with more efficient equipment and reconductors transmission and primary feeder lines yields a total recoverable resource of $233 \mathrm{AMW}$. This resource can be broken down as follows:

replacing distribution transformers can recover approximately 78 AMw; reconductoring transmission lines, 48 AMW; reconductoring distribution feeders, 99 AMW; and replacing substation transformers, 8 AMW.

A combination of the voltage upgrade option and application of transformer replacement and reconductoring in the balance of the systems was estimated to provide 293 AMW savings at 2 cents $/ \mathrm{kWh}$ and $380 \mathrm{AMW}$ at 5.5 cents $/ \mathrm{kWh}$. Comparing these results to the cost at which $T \& D$ system improvenents are considered cost effective by the NWPPC, a potential resource of 335 AMW was estimated to be available at 5 cents/kWh in 1985 dollars.

The conservation resources available by applying the above loss reduction

- measures only to POU systems in the BPA service area were estimated using the methodology developed in this study. This analysis indicated that the magni-

- tude of POU resources are approximately $40 \%$ of the corresponding regional resources. The two exceptions (reconductoring primary feeders and transmission 
lines) reflect differences in the proportion of these components in the stocks of each type of utility. The largest conservation resource available on POU systems, as was also true for the regional case, resulted from the combination of the voltage upgrade resource with loss recovery provided by the replacement of the transformers and 1 ines not affected by this measure. This combined POU supply curve indicated resources of 125 and $150 \mathrm{AMW}$ at 2 and 5.5 cents/kwh, respectively, in 1980 dollars. At 5 cents $/ \mathrm{kWh}$ in 1985 dollars (the NWPPC costeffectiveness criterion), the T\&D conservation potential of POU systems was . estimated to be approximately $140 \mathrm{AMW}$.

The supply function analysis performed in this study is considered to include the effects of biases that were unavoidably acquired in survey data collected, of necessity, from utilities in the Pacific Northwest. On an aggregate basis, these biases are expected to make the analyses somewhat conservative (i.e., more resource may be available at a given cost than was estimated).

The level of detail to which components were characterized and losses were estimated provides a more substantial basis for assessing the conservation potential of T\&D systems on a regional scale than has existed before in either the Pacific Northwest or other regions. 


\section{REFERENCES}

Bonneville Power Administration (BPA). 1981. Distribution System Efficiency Improvement Handbook. Portland, Oregon.

Callaway, J. W., and J. G. De Steese. 1986. Customer System Efficiency Improvement Assessment: Description and Examination of System Characterization Data. PNL-5955, Pacific Northwest Laboratory, Richland, Washington.

CRC Handbook of Chemistry and Physics. 1981. 62nd Edition, Robert C. Weast and Melvin J. Astle eds., CRC Press, Inc., Boca Raton, Florida.

Electric Power Research Institute (EPRI). 1979. TAG-Technical Assessment Guide. Special Report PS-1201-SR, Palo Alto, California.

Electric Power Research Institute (EPRI). 1983. Improved Methods for Distribution Loss Evaluation. EPRI EL-3261, Vol.1, PaTo Alto, California.

Electrical World. 1983. Directory of Electric Utilities, 1982-1983. 92nd Edition, McGraw-Hill Book Company, New York, New York.

Northwest Power Planning Council (NWPPC). 1983. 1983 Northwest Conservation and Electric Power Plan. Portland, Oregon.

Northwest Power Planning Council (NwPPC). 1986. 1986 Northwest Conservation and Electric Power Plan. Portland, Oregon.

Standard Handbook for Electrical Engineers. 1978. 11th Edition, Donald G. Fink and H. Wayne Beaty eds., McGraw-Hill Book Company, New York, New York.

Sun, D. I. H., et a1. 1980. Calculations of Energy Losses in a Distribution System. Energy Systems Research Center, University of Texas, Arijington, Texas.

Whitman, Requardt, and Associates. 1986. Handy-Whitman Index of Public Utility Construction Costs. Baltimore, Maryland. 

APPENDIX

LOSS REDUCTION METHODOLOGY 


\section{APPENDIX}

\section{LOSS REDUCTION METHODOLOGY}

An objective of the CSEI study was to review established loss estimation methods and recommend a standard method suitable for estimating the regional loss recovery resource that could resuit from efficiency improvements in BPA customer systems. Three principal problems had to be addressed in the pursuit of this objective:

1. There appeared to be no method available that estimates regional losses directly.

2. Currently-used methods are system-specific.

3. Even the most simple system-specific methods have data requirements that exceed 1) the system-characterization data that have been collected to date and 2) possibly any volume of data that might be costeffectively collected.

While part of the data availability problem diminished as the system characterization data base was developed (Callaway and De Steese 1986), it became clear that any method ultimately considered as the "standard" method needed to accommodate variable data quality.

The following material summarizes the methods reviewed and the method that was selected.

\section{A.1 METHODS REVIEHED}

Four distinguishable loss estimating methods were reviewed for possible use as a standard method in the CSEI Assessment Project.

1. the method described in the BPA Distribution System Efficiency Improvement Handbook (BPA 1981)

2. the SCALE code (EPRI 1983) 
3. the detailed calculation of distribution losses (EPRI 1983)

4. the DSAS method (Sun et al. 1980).

The approach described in the BPA publication (BPA 1981) was developed by $\mathrm{CH}_{2} \mathrm{M}-\mathrm{Hij} 1 \mathrm{l}$ and is presented in the form of a field estimating guidebook. The method reduces large amounts of design theory to simple calculations that summarize more complex principles of distribution system design. By using the tables and worksheets in this manual that account for the major loss sources in a system, field personnel can compute losses with a hand calculator. While this approach is possibly useful for evaluating losses in a small portion of a system, applying it to whole systems would be laborious and difficult because of the data requirements. It does not appear to be suitable, moreover, for the evaluation of a complete distribution system, or in this case, a regional set of systems.

The SCALE method, an acronym for "Simplified Calculation of Loss Equations" was designed for computer implementation (EPRI 1983). Developed by the westinghouse Electric Corporation for EPRI, SCALE is composed of the following five models that can be used independently:

1. Economics

2. Primary and Lateral Line Losses

3. Substation and Distribution Losses

4. Distribution Power Losses

5. Distribution Area Losses.

The SCALE method is much less complex than either of the methods described below and incorporates loss equations and economic cost estimating techniques that are generally accepted in the industry. In a comparison of methods, SCALE estimated energy losses 7 and $14 \%$ higher in two test cases, respectively, than the losses predicted by the more detailed method developed for EPRI (EPRI 1983).

A detailed method was developed by EPRI for evaluating distribution losses by individual elements in a distribution system (EPRI 1983). This method requires a very large data base, including metered substation energy and enduse billing for a year, and 24-hour load profiles for transformers serving each . 
class of consumer. The difference between energy entering the systern and that received by consumers is attributed to losses. This approach assumes that there are no unmetered loads or theft in the system. Using an electrical load model to account for unmeasured elements and estimated end-use load profiles and statistical procedures, losses are divided and allocated to individual components in the system. The method is extremely complex and involves computer file development that could require many man-months per distribution system.

- Despite the extreme detail of the test case reported, the method was unable to account for over $13 \%$ of the total distribution system loss.

The fourth method considered was developed by the Energy Systems Research Center of the University of Texas at Arlington, Texas. It integrates daily load shapes with a load flow procedure to produce an energy model. Feeder performance is analyzed by a load flow program capable of modeling different load component characteristics, load imbalance, and system configuration. The method introduces the concept of the "load window" to describe the distribution of end use loads. The method was demonstrated by case studies of feeders owned by the Public Service Company of New Mexico (Sun et a1. 1980).

This method has been developed by more recent studies performed with the cooperation of other utilities and has been aggregated into the Distribution System Analysis and Simulation (DSAS) Program. This is a highly analytic method written for an IBM 370/155 computer that totally characterizes the system from substation to end-use loads. At the time of the CSEI Assessment loss analysis, the user's manua? for the DSAS program was not available. While this is probably the most rigorous method developed to date, it appears to require much more system characterization data than could be cost-effectively generated on a region-wide level.

\section{A.2 SELECTING A STANDARD METHOD}

A principal difficulty in adapting system-specific loss estimating methodology to the task of a regional assessment is that the data collection effort is proportional to the number of representative system descriptions needed. It - was estimated that 20 or more detailed utility system descriptions would be 
needed to perform a representative loss apportionment to the principal lossgenerating components of the Pacific Northwest power system using any of the candidate approaches in their original form. The complexity of both the detailed and DSAS methods for system-specific analysis precluded their use altogether.

On the other hand, the accuracy of the BPA method was felt to be more appropriate to individual component loss studies for engineering purposes than for a regional loss estimation. Use of some elements of this method did prove to be useful, however, for some portions of the loss calculations for the supply-curve estimates. Of the four approaches reviewed, the Westinghousedeveloped SCALE method appeared to represent the best compromise. Its use results in acceptable accuracy, and its data requirements are moderate. Elements of this methodology, modified to suit the needs and limitations of the CSEI Assessment were, therefore, selected as parts of a standard approach for estimating the Ioss reduction potential of BPA customer T\&D systems. 


\section{DISTRIBUTION}

No. of

Copies

OFFS ITE

30 W. M. Warwick

MS / KES

Bonneville Power Administration

P.0. Box 3621

Portland, OR 97208

M. J. King

SYNERGIC Resources Corp.

Suite 820

4th and Pike Building

Seattie, WA 98101

2 DDE Techical Information Center

\section{ONSITE}

DOE Richland Dperations Office

J. J. Sutey/D. R. Segna
No. of

Copies

38 Pacific Northwest Laboratory

J. W. Callaway (10)

C. A. Counts

R. F. Darwin

J. G. De Steese (10)

W. H. Doggett

P. L. Hendrickson

J. W. Johnston

M. S. Klan

A. D, Lee

R. U. Nesse

T. J. Secrest

Z. T. Taylor

R. C. Tepe?

Publishing Coordination $\mathrm{MH}$ (2)

Technical Report Files (5) 


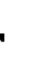

